\title{
Guía y claves para el reconocimiento de las subfamilias, géneros y especies de Syllidae registradas a lo largo de la costa de Chile, archipiélago Juan Fernández e isla de Pascua (Annelida: Phyllodocida: Syllidae)
}

Guide and keys for the identification of the subfamilies, genera and species of Syllidae registered along the Chilean coast, the Juan Fernández Archipelago and Easter Island (Annelida: Phyllodocida: Syllidae) Guillermo San Martín ${ }^{1}$, Nicolás Rozbaczylo² \& Oscar Díaz-Díaz ${ }^{3}$

\section{Resumen}

Se presenta una revisión actualizada de las especies de poliquetos de la familia Syllidae registradas hasta ahora en el océano Pacífico suroriental a lo largo de la costa de Chile, desde la localidad de Arica (18 $28^{\prime}$ S) en el límite norte, hasta cabo de Hornos (5556' S), en el extremo sur, incluidas las aguas interiores en el área de canales y fiordos australes, en el archipiélago Juan Fernández (3340' S, 7900' O) y en isla de Pascua (2709' S, $109^{\circ} 23^{\prime}$ O). Se proporcionan claves para la determinación de las subfamilias, géneros y especies de silidos registradas hasta ahora en la región. Para cada una de las especies consideradas válidas se incluye una lista cronológica de los autores que han estudiado ejemplares de esa especie recolectados dentro de los límites geográficos del mar de Chile. También se dan a conocer todas las localidades de recolección de cada especie, en orden cronológico y latitudinal, con el nombre del autor y la fecha de la publicación en que las localidades fueron señaladas. Se entrega información sobre morfología, biología, ecología y sistemática de los sílidos en general. El número de especies de sílidos registrados a la fecha en las tres áreas consideradas dentro de los límites del mar chileno es de 63, de las cuales 56 se distribuyen en el litoral costero continental de Chile, cinco en el archipiélago Juan Fernández y ocho en isla de Pascua. Dichas especies pertenecen a las cinco subfamilias reconocidas para esta familia, más algunos géneros de ubicuación incierta, llegando hasta ahora a un total de 25 géneros. De las 63 especies de sílidos registradas hasta ahora a lo largo de la costa de Chile, incluida la zona de canales y fiordos australes, archipiélago Juan Fernández e isla de Pascua, 32 registran como localidad tipo la costa de Chile, y 2 el archipiélago Juan Fernández, y de ellas 22 especies son consideradas endémicas de Chile.

Palabras clave: Catálogo, Poliquetos, Sílidos, Chile.

\section{Abstract}

An updated review of polychaete species of the family Syllidae registered so far in the southeastern Pacific Ocean along the coast of Chile, from the locality of Arica $\left(18^{\circ} 28^{\prime} \mathrm{S}\right)$ in the northern border to Cape Horn (55 $56^{\prime}$ 'S) at the southern end, in Juan Fernández Archipelago (3340' S,

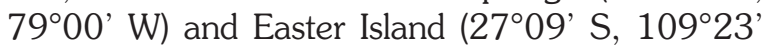
$\mathrm{W})$ is presented. Keys to the determination of the subfamilies, genera and species of syllids registered in Chile are provided. A chronological list of the authors who have reviewed specimens for each

1 Departamento de Biología (Zoología), Laboratorio de Biología Marina e Invertebrados, Facultad de Ciencias, Universidad Autónoma de Madrid, Canto Blanco, 28049

Madrid, España. guillermo.sanmartin@uam.es

2 FAUNAMAR Ltda. Consultorías Medio Ambientales e Investigación Marina, Santiago, Chile faunamarconsultores@gmail.com, $\triangle$ nrozbaczylo@bio.puc.cl

3 Laboratorio de Biología de Poliquetos, Instituto Oceanográfico de Venezuela, Universidad de Oriente, Venezuela ofdiazd@gmail.com 
of the species considered valid is included. All collecting localities of each species in chronological and latitudinal order, with the author's name and the date of the publication in which the locations were identified are included. Information on morphology, biology, ecology and systematics of syllids in general is provided. The number of syllids registered so far along the Chilean coast is 63 species, of these 56 species have been recorded to the continental coastal littoral of Chile, five species in Juan Fernández Archipelago and eight species in Easter Island, in 25 genera, distributed in five subfamilies, in the three areas considered within the limits of the Chilean sea. Of the 63 species of syllids recorded so far along the coast of Chile, including the austral channels and fjords, the Juan Fernández Archipelago and Easter Island, 32 record the coast of Chile as type locality, two the Juan Fernández Archipelago, and of them 22 species are considered endemic to Chile.

Key words: Catalogue, Polychaetes, syllids, Chile.

\section{INTRODUCCIÓN}

Los poliquetos constituyen uno de los taxa más importantes en las comunidades marinas bentónicas de todo el mundo, en términos de abundancia y diversidad (Fauchald \& Jumars, 1979; Beesley et al. 2000). En la fauna chilena representan el tercer taxón de invertebrados marinos conocidos, más abundantes en cuanto al número de especies, tan solo después de los crustáceos y moluscos (Lee et al. 2008; Rozbaczylo \& Moreno, 2010).

A lo largo de la costa de Chile, desde Arica (18 28' S) hasta el Cabo de Hornos (5556' S) y en sus islas oceánicas (archipiélago Juan Fernández, 3340' S, 7900' O e isla de Pascua, 2709' S, $190^{\circ} 23^{\prime}$ O), se han registrado hasta ahora un total de 593 especies de poliquetos bentónicos repartidas en 47 familias (Rozbaczylo et al. 2017), siendo Syllidae la familia con mayor número de especies registradas a lo largo de la costa de Chile. El primer registro de una especie de sílido en Chile fue realizado por Blanchard (1849) como Syllis stenura Blanchard, 1849, para la localidad de Ancud (= San Carlos de Chiloé). Sin embargo, esta especie fue considerada como indeterminable por Hartman (1959), debido a una descripción incompleta que no permite reconocerla.

El objetivo de este trabajo es entregar una lista actualizada de las especies de poliquetos de la familia Syllidae registradas a lo largo de la costa de Chile, en el archipiélago Juan Fernández y en isla de Pascua, con claves de identificación para las subfamilias, géneros y especies registradas hasta ahora en la región con la finalidad de que sirvan de apoyo para los investigadores que deben realizar una determinación rápida y confiable de ejemplares de esta familia de poliquetos, así como para que sirva de estímulo y base para futuros trabajos sobre esta familia, no solo en Chile, sino en Sudamérica.

\section{Materiales y métodos}

Para la elaboración de este trabajo nos hemos basado inicialmente en la información contenida en el Catálogo de poliquetos de Chile (Rozbaczylo, 1985), la cual ha sido actualizada considerando la información taxonómica disponible hasta la fecha (Rozbaczylo et al. 2017).

En general, sólo hemos incluido información contenida en trabajos taxonómicos y sólo en algunos casos hemos considerado citas contenidas en trabajos ecológicos cuando ellos representan nuevos registros de géneros $y / 0$ especies en determinadas localidades geográficas.

Tanto los nombres genéricos como los específicos se presentan ordenados alfabéticamente. Cada nombre genérico va acompañado de su autor y año de la descripción y las páginas en que se encuentra la descripción original señaladas entre paréntesis. Cada nombre específico es seguido del nombre del descriptor y del año de publicación; en paréntesis, se señala el número de las páginas en que se encuentra la descripción original y de las láminas y figuras, si las hay; a continuación se indica la localidad tipo. Si un nombre específico ha sido considerado como sinónimo, o si una especie ha sido reubicada en otro género, después de la localidad tipo se indica la posición taxonómica actual y el autor que propuso dicho cambio, si este es reciente, o si se considera de interés como referencia para revisiones futuras. Para cada una de las especies consideradas válidas se incluye, bajo los subtítulos "Referencias 
para Chile" u "Otras referencias para Chile", una lista cronológica de los autores que han estudiado ejemplares de esa especie recolectados dentro de los límites geográficos del mar de Chile. Bajo los subtítulos "Localidades citadas para Chile" u "Otras localidades citadas para Chile" se enumeran todas las localidades de recolección de la especie, en orden cronológico y latitudinal, con el nombre del autor y la fecha de la publicación en que tales localidades fueron señaladas. Cuando una especie ha sido encontrada más de una vez en la misma localidad, se cita primero la referencia más antigua.

Se proporciona una tabla resumen sobre la diversidad y distribución de los sílidos a lo largo de las costa de Chile, archipiélago Juan Fernández e isla de Pascua (Tabla 1, Fig. 1), para lo cual se establecieron doce áreas geográficas denominadas de la siguiente manera: IQ: $18^{\circ}-22^{\circ} \mathrm{S}$ (Arica a Tocopilla); AN: $22^{\circ}-26^{\circ} \mathrm{S}$ (Tocopilla a Chañaral); CC: $26^{\circ}-30^{\circ} \mathrm{S}$ (Chañaral a Coquimbo); CV: $30^{\circ}-$ $34^{\circ} \mathrm{S}$ (Coquimbo a Pichilemu); TA: $34^{\circ}-38^{\circ} \mathrm{S}$ (Pichilemu a Lebu); VA: $38^{\circ}-41^{\circ} \mathrm{S}$ (Lebu a Maullin); $\mathrm{CH}$ : $40^{\circ}-46^{\circ} \mathrm{S}$ (Puerto Montt a isla Tenquehuén); GP: $46^{\circ}-50^{\circ} \mathrm{S}$ (isla Tenquehuén a isla Madre de Dios); EM: $50^{\circ}-54^{\circ} \mathrm{S}$ (isla Madre de Dios a isla Carlos); CB: $54^{\circ}-56^{\circ} \mathrm{S}$ (isla Carlos a Cabo de Hornos); JF: archipiélago Juan Fernández; (P) isla de Pascua.

En este trabajo la familia se ha organizado siguiendo las clasificaciones más recientes en uso actualmente (Aguado \& San Martín, 2009; Aguado et al. 2007, 2012; Nygren, 2004; San Martín \& Aguado, 2014). Rouse \& Fauchald (1997) colocaron a los Syllidae en el clado "Palpata, Aciculata, Phyllodocida".

\section{RESULTADOS}

La fauna de Syllidae registrada hasta ahora a lo largo de la costa de Chile, desde Arica (18 $28^{\circ}$ S), en el límite norte, hasta Cabo de Hornos (5556' S), en el límite sur, es de 56 especies, cinco especies en el archipiélago Juan Fernández (3340' $\left.\mathrm{S}, 7^{\circ} 00^{\prime} \mathrm{O}\right)$ y ocho especies en isla de Pascua (2709' S, $109^{\circ} 23^{\prime}$ O), llegando hasta ahora a un total de 63 especies repartidas en 25 géneros y distribuidas en cinco subfamilias, más un grupo de Incertae sedis, en las tres áreas consideradas.

Estos números podrían incrementarse en la medida que aumenten las prospecciones en áreas que aún no han sido completamente investigadas, tales como la zona de los canales y fiordos australes chilenos, que se extiende aproximadamente entre los $41,5^{\circ} \mathrm{S}$ y $55,0^{\circ} \mathrm{S}$, desde Puerto Montt a cabo de Hornos (Silva \& Palma, 2006) y las islas oceánicas: archipiélago Juan Fernández, isla de

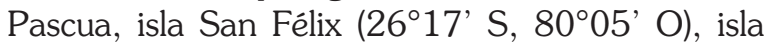
San Ambrosio (26²0' S, $79^{\circ} 58^{\prime}$ O) e isla Salas y Gómez (26²7' S, $105^{\circ} 28^{\prime}$ O), especialmente en estas tres últimas islas de las cuales no se cuenta con información (Rozbaczylo et al. 2017).

De las 63 especies de sílidos registradas hasta ahora a lo largo de la costa de Chile, incluida la zona de canales y fiordos australes, archipiélago Juan Fernández e isla de Pascua, 32 registran como localidad tipo la costa de Chile, y 2 el archipiélago Juan Fernández, y de ellas 22 especies son consideradas potencialmente endémicas de Chile, si bien resulta difícil y arriesgado afirmar tal cosa con anélidos poliquetos.

Las cinco especies de sílidos registradas en el archipiélago Juan Fernández son: Brachysyllis infuscata (Ehlers, 1901), Myrianida (?) simplex (Ehlers, 1900), Sphaerosyllis hirsuta Ehlers, 1897, Trypanedenta gigantea (McIntosh, 1885), y Syllis hyalina juanensis Augener, 1922. De ellas, sólo la última ha sido registrada hasta ahora sólo en la localidad tipo, isla Robinson Crusoe, y es considerada endémica del archipiélago Juan Fernández.

Las ocho especies de sílidos registradas hasta ahora en isla de Pascua son: Paraehlersia ferrugina (Langerhans, 1881), Sphaerosyllis hystrix Claparède, 1863, Exogone verugera (Claparède, 1868), Haplosyllis spongicola (Grube, 1855), Branchiosyllis verruculosa (Augener, 1913), Syllis prolifera Krohn, 1852, Salvatoria limbata (Claparède, 1868) y Syllis cornuta Rathke, 1843. De ellas, las tres últimas especies también están registradas en la costa de Chile, y ninguna especie hasta ahora es considerada endémica. Estas especies son en su mayoría de los mares europeos, $y$ es muy posible que en realidad se trate de otras especies, dada la lejanía y el aislamiento de isla de Pascua, pero sería necesaria una revisión crítica de los ejemplares. Recientemente, Soto \& San Martín (2017), citan el género Nudisyllis Knox \& Cameron, 1970 y una especie de Epigamia, pero al no dar una denominación específica, no las 


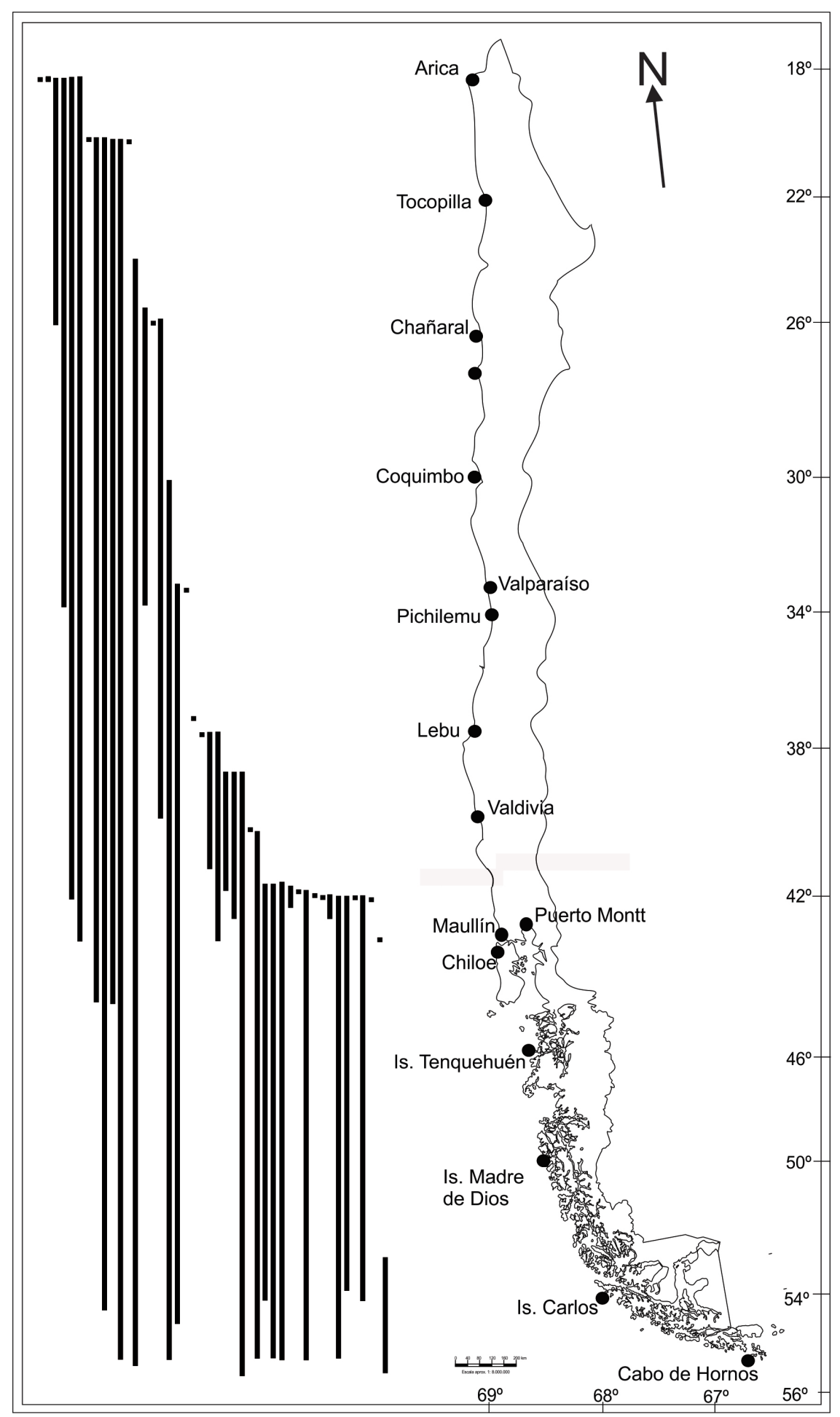

Fig. 1. Extensión latitudinal de las 56 especies de silidos registradas a lo largo

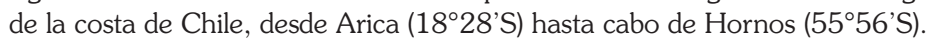
Cada barra vertical representa la distribución de una especie. 
Tabla 1. Diversidad y zoogeografía de los silidos registrados en Chile: IQ: $18^{\circ}-22^{\circ} \mathrm{S}$ (Arica-Tocopilla); AN: $22^{\circ}-26^{\circ} \mathrm{S}$ (Tocopilla-Chañaral); CC: $26^{\circ}-30^{\circ} \mathrm{S}$ (Chañaral-Coquimbo); CV: $30^{\circ}-34^{\circ} \mathrm{S}$ (Coquimbo-Pichilemu); TA: $34^{\circ}-38^{\circ} \mathrm{S}$ (Pichilemu-Lebu); VA: $38^{\circ}-41^{\circ} \mathrm{S}$ (Lebu-Maullin); $\mathrm{CH}$ : $40^{\circ}-46^{\circ} \mathrm{S}$ (Puerto Montt-isla Tenquehuén); GP: $46^{\circ}-50^{\circ} \mathrm{S}$ (isla Tenquehuén-isla Madre de Dios); EM: $50^{\circ}-54^{\circ} \mathrm{S}$ (isla Madre de Dios-isla Carlos); $\mathrm{CB}: 54^{\circ}-56^{\circ} \mathrm{S}$ (isla Carlos-Cabo de Hornos); JF: archipiélago Juan Fernández; (P) isla de Pascua

\begin{tabular}{llllllllllllll}
\hline SUBFAMILIAS & \multicolumn{11}{c}{ Áreas } \\
\hline ESPECIES & IQ & AN & CC & CV & TA & VA & CH & GP & EM & CB & JF & $P$ \\
\hline
\end{tabular}

\section{Eusyllinae Incertae sedis}

Amblyosyllis granosa Ehlers, 1897

Brachysyllis infuscata (Ehlers, 1901)

Neopetitia amphophthalma (Siewing, 1955)

Paraehlersia ferrugina (Langerhans, 1881)

Paraehlersia kawesqar Soto \& San Martín, 2017

Perkinsyllis longisetosa Hartmann-Schröder, 1965

\section{Subfamilia Anoplosyllinae}

Anoplosyllis sexoculata (Hartmann-Schröder, 1962)

Syllides articulosa Ehlers, 1897

Syllides japonica Imajima, 1966

\section{Subfamilia Autolytinae}

Epigamia charcoti (Gravier, 1906)

Epigamia (?) maclearanus (McIntosh, 1885)

Myrianida (?) simplex (Ehlers, 1900)

Proceraea micropedata (Hartmann-Schröder, 1965)

\section{Subfamilia Exogoninae}

Erinaceusyllis bidentata (Hartmann-Schröder, 1974)

Erinaceusyllis carrascoi Soto, San Martín \& Peñaloza, en prensa

Erinaceusyllis (?) paucicirra papillata (Hartmann-Schröder, 1962)

Erinaceusyllis perspicax (Ehlers, 1908)

Erinaceusyllis (?) subterranea (Hartmann-Schröder, 1965)

Exogone heterosetoides Hartmann-Schröder, 1979

Exogone heterosetosa McIntosh, 1885

Exogone verugera (Claparède, 1868)

Exogone yagan Soto, San Martín \& Peñaloza, en prensa

Parapionosyllis brevicirra Day, 1954

Parexogone homosetosa (Hartmann-Schröder, 1965)

Parexogone minuscula (Hartman, 1953)

Parexogone parahebes (Hartmann-Schröder, 1965)

Parexogone tasmanica (Hartmann.Schröder, 1989) 
(continuación Tabla 1)

\begin{tabular}{lllllllllllllll}
\hline SUBFAMILIAS & Áreas \\
\hline ESPECIES & IQ & AN & CC & CV & TA & VA & CH & GP & EM & CB & JF & P
\end{tabular}

Prosphaerosyllis (?) brandhorsti (Hartmann-Schröder, 1965)

Prosphaerosyllis (?) kerguelensis (McIntosh, 1885)

Prosphaerosyllis (?) sublaevis (Ehlers, 1913)

Salvatoria limbata (Claparède, 1868)

Salvatoria nutrix (Monro, 1936)

Salvatoria rhopalophora (Ehlers, 1897)

Sphaerosyllis capensis chilensis Hartmann-Schröder, 1962

Sphaerosyllis dubiosa Hartmann-Schröder, 1962

Sphaerosyllis hirsuta Ehlers, 1897

Sphaerosyllis hystrix Claparède, 1863

\section{Subfamilia Syllinae}

Branchiosyllis verruculosa (Augener, 1913)

Haplosyllis spongicola (Grube, 1855)

Syllis albae Álvarez-Campos \& Verdes, 2017

Syllis anoculata (Hartmann-Schröder, 1962)

Syllis anops Ehlers, 1897

Syllis cornuta Rathke, 1843

Syllis filidentata (Hartmann-Schröder, 1962)

Syllis hyalina juanensis Augener, 1922

Syllis luteoides (Hartmann-Schröder, 1962)

Syllis magdalena Wesenberg-Lund, 1962

Syllis magellanica Augener, 1918

Syllis palifica Ehlers, 1901

Syllis pectinans Haswell, 1920

Syllis prolifera Krohn, 1852

Syllis prolixa Ehlers, 1901

Syllis sclerolaema Ehlers, 1900

Syllis tamarae Álvarez-Campos \& Verdes, 2017

Syllsi tripantu Álvarez-Campos \& Verdes, 2017

Syllis valida Grube, 1857

Syllis variegata Grube, 1860

Trypanedenta gigantea (McIntosh, 1885)

Trypanosyllis parazebra Hartmann-Schröder, 1965

Trypanosyllis zebra (Grube, 1860)

\section{Subfamilia Eusyllinae}

Eusyllis nuchalata Hartmann-Schröder, 1965

Odontosyllis magnanuchalata Hartmann-Schröder, 1965

Pionosyllis kerguelensis (McIntosh, 1885) 
incluimos en el catálogo.

El número de especies registradas a lo largo de la costa de Chile, en isla de Pascua y en el archipiélago Juan Fernández es considerado comparativamente bajo en relación con la gran extensión de costa, y la diversidad climática y de hábitats, por lo que sería de gran importancia llevar a cabo estudios particulares sobre esta familia, que permitan incrementar el número y calidad de las descripciones de los sílidos en Chile, en especial en aquellas áreas poco exploradas, como son los fiordos y canales australes, y las islas y archipiélagos alejados de la costa continental chilena. Uno de los problemas que nos encontramos al estudiar la fauna de sílidos en Chile es que la mayor parte de las citas provienen de trabajos muy antiguos, y no existen redescripciones modernas que permitan una correcta y segura identificación. En algunos casos resulta casi imposible saber si una determinada especie es válida, ya que las descripciones son muy breves o no contienen caracteres diagnósticos y muchas veces, el material tipo ha desaparecido.

En general, los sílidos son extraordinariamente abundantes, pequeños y difíciles de identificar, por lo que resultan poco atractivos. Por eso mediante este trabajo esperamos impulsar y facilitar el estudio de esta familia de poliquetos en Chile.

\section{Generalidades de los sílidos}

Esta sección sobre generalidades, morfología y reproducción de la familia Syllidae está basada principalmente en San Martín (2003), Aguado et al. (2012), San Martín \& Aguado (2014) y San Martín \& Worsfold (2015).

Los silidos son poliquetos de talla pequeña a mediana, de 2 a $3 \mathrm{~mm}$ de longitud y unos 15 a 30 setígeros, hasta algunos de mucho mayor tamaño, hasta $140 \mathrm{~mm}$ y 200 setígeros, como una especie de Trypanosyllis Claparède, 1864, descrita recientemente en aguas profundas del $\mathrm{N}$ de España, de 196 mm de longitud, 4,5 -7 mm de anchura, con 485 setígeros (Álvarez-Campos et al., en prensa). Son muy abundantes y diversos en los hábitats bentónicos poco profundos, pero también se encuentran en áreas profundas; sin embargo, están ausentes en aguas dulces y salobres, por lo que apenas los hay en los estuarios. Son muy comunes en sustratos duros, llevando una vida errante entre algas, concreciones calcáreas, grietas y en el interior de grietas porosas, pero también se encuentran en sedimentos marinos, especialmente en arena gruesa, donde llevan un modo de vida intersticial. También, muchas especies viven asociadas a otros organismos marinos, sobre todo esponjas, colonias de hidrozoos y octocorales, en especial en áreas tropicales, y también en comunidades de mitílidos como Perumytilus purpuratus (Lamarck, 1819) y de tunicados como Pyura chilensis Molina, 1782.

Pueden constituir más del $50 \%$, incluso hasta el $70 \%$, de las especies de poliquetos en algunos sustratos, por lo que resultan muy importantes en los estudios sobre bentos marino. Por el contrario, debido a su pequeño tamaño suelen pasar desapercibidos y no son considerados en la mayor parte de los estudios de ecología bentónica marina. Además, son bastante difíciles de identificar, tanto por su pequeño tamaño como por la falta de estudios taxonómicos en muchas áreas y de monografías con claves y descripciones detalladas que permitan una identificación rápida y correcta. Los silidos son muy fáciles de reconocer a nivel de familia, debido a que tienen una modificación muy conspicua del tubo digestivo, el proventrículo, que constituye la autopomorfía de la familia (Glasby, 2000). La taxonomía y sistemática de los sílidos son también complejas y difíciles, nuevamente por su pequeño tamaño, como por los numerosos taxa existentes (unos 74 géneros y 700 especies a nivel mundial, San Martín \& Aguado, 2014), y lo difícil de observar correctamente los caracteres. Es muy recomendable efectuar la comparación de los ejemplares con las descripciones, independientemente de la claves. Es necesario hacer notar que los ejemplares fijados pierden la pigmentación después de un tiempo, y también que los ejemplares jóvenes poseen los apéndices más cortos en proporción a los ejemplares de mayor tamaño.

\section{Principales caracteres morfológicos}

Cuerpo. Típicamente, el cuerpo tiene una sección cilíndrica (Figs. 2 A, B, E), pero en algunos géneros es aplanado $y$, a veces, con forma de cinta como en los miembros del género Trypanosyllis Claparède, 1864. La superficie del cuerpo es lisa (Figs. 2 A-C), pero algunos géneros presenta papilas en el dorso (Fig. 2 D), que se pueden 
extender a los parápodos y la superficie ventral.

Prostomio. El prostomio puede ser semicircular, pentagonal u oval y lleva típicamente cuatro ojos, con un par de manchas oculares anteriores, no siempre presentes y las cuales se pierden fácilmente tras la fijación; tres antenas, que pueden ser lisas (Figs. $2 \mathrm{~B}, \mathrm{E}$ ) o articuladas (= moniliformes) (Figs. 2 A, C), cortas o largas; un par de palpos triangulares, que pueden estar totalmente separados uno del otro (Fig. 2 D), fusionados en la base o fusionados en toda su longitud (Fig. 2 E).

Cirros tentaculares (= peristomiales). Normalmente hay dos pares (Figs. $2 \mathrm{~A}-\mathrm{C}, \mathrm{E}$ ), pero en algunos géneros hay solamente un par (Fig. 2 D); pueden ser lisos (Figs. 2 B, D-E) o articulados (= moniliformes) (Figs. 2 A, C), cortos o largos.

Órganos nucales. Hay dos tipos principales: hendiduras ciliadas, que son las más frecuentes (Fig. 2 B) o proyecciones nucales (Fig. 2 E).

Parápodos. Son unirrámeos (excepto en algunos segmentos, durante la reproducción), con cirro dorsal, lóbulo parapodial, cirro ventral, sedas, y acícula (Figs. 3 A-D).

Cirros dorsales. Pueden ser largos (Figs. 2 A-B) o cortos (Fig. 2 D), alternando entre largos y cortos, lisos (Figs. 2 B, D) o moniliformes (Figs. 2 A, C); típicamente son filiformes, pero pueden ser de formas muy variadas.

Cirros ventrales. Están presentes, excepto en la subfamilia Autolytinae (Fig. 3 D), aunque en realidad es muy posible que estén fusionados a los lóbulos parapodiales.

Faringe. Normalmente es recta, pero en algunos géneros puede aparecer con numerosas vueltas y a veces muy delgada y compleja (Fig. 2 E).

Armadura faríngea. La mayoría de los géneros poseen un solo diente faríngeo (Figs. 2 A-D); sin embargo, algunos géneros tienen una corona de dentículos en la abertura faríngea, llamada trépano, con (Fig. $3 \mathrm{~F}$ ) o sin diente faríngeo (Fig. $3 \mathrm{G}$ ), éste puede ser completo o incompleto, y los dentículos pueden estar dirigidos hacia la parte anterior o hacia la parte posterior del cuerpo (Fig. 3 G). Por el contrario, los miembros de la subfamilia Anoplosyllinae Aguado y San Martín, 2009 carecen de cualquier tipo de armadura faríngea.

Proventrículo. Tanto el tamaño (número de segmentos que ocupa) como el número de hileras de células musculares varían entre especies, pero no es exacto, ya que hay cierta variabilidad y cambia con la ontogenia.

Sedas. Las sedas de los sílidos son, típicamente, compuestas heterogonfas, con sedas capilares simples dorsales y ventrales en los parápodos posteriores. Sin embargo, pueden sufrir muchas modificaciones; algunas pueden ser alargadas, similares a las espinígeras de los neréididos, denominadas pseudoespinígeras (Fig. 4 D). Las falcígeras son típicamente bidentadas, con ambos dientes similares (Fig. 4 B), el proximal más pequeño que el distal (Fig. $4 \mathrm{~F}$ ) o el proximal mayor que el distal (Fig. 4 C); también hay artejos unidentados (Fig. 4 A) y otros con forma de garfio o garra como en las especies del género Branchiosyllis (Fig. 4 N). Los artejos poseen una sola fila de espinas marginales, que pueden ser largas (Fig. 4 E) o cortas (Figs. 4 C, F), o incluso estar ausentes $y$, en ese caso, los artejos son lisos. A veces, puede haber sedas gruesas simples debido a la pérdida de los artejos y engrosamiento de los mangos (Fig. 4 G) o por fusión de los artejos y los mangos (Fig. $4 \mathrm{H}$ ). Las sedas simples capilares dorsales y ventrales suelen ser muy delgadas, bífidas o unidentadas, con o sin espinas subdistales o gruesas con un diente subdistal prominente y extremo distal bífido (Fig. $4 \mathrm{M}$ ) o entero. Típicamente, esas sedas capilares simples están presentes solo en los parápodos posteriores.

Acículas. Se pueden encontrar muchas formas: rectas y puntiagudas (Fig. 4 I), acuminadas (Fig. $4 \mathrm{~K}$ ), dobladas en ángulo recto (Fig. $4 \mathrm{~J}$ ), distalmente redondeadas (Fig. 4 L), y muchas más.

\section{Reproducción}

En los sílidos hay dos tipos principales de reproducción: epigamia y esquizogamia. 
La epigamia en silidos es bastante similar a la de otros poliquetos, aunque es algo diferente en cuanto a la aparición de notosedas largas y delgadas para la natación (sedas natatorias) (Fig. 5 A), en los parápodos medios y posteriores. Hay dos tipos de epigamia: sin incubación o con incubación de los huevos. La incubación de los huevos puede ser dorsal, mediante notosedas capilares, o ventral, sujetos al nefridióporo. En este último caso, los juveniles crecen sujetos al cuerpo de la madre, pero en la incubación dorsal se forman larvas (San Martín, 2005).

La esquizogamia se realiza mediante estolones sexuales. Hay dos tipos de esquizogamia: por escisiparidad (formando un solo estolón) o gemmiparidad (formando una cadena de estolones) (Figs. 6 A). También hay casos en los que se forman racimos de estolones (Fig. 6 B) (Trypanedenta Imajima \& Hartman, 1964; ver Álvarez-Campos et al. 2017), o con estolones en ramificaciones (Ramisyllis Glasby, Schroeder \& Aguado, 2012).

Los estolones de los Syllinae no tienen dimorfismo sexual, pero son fácilmente distinguibles porque los estolones masculinos almacenan espermatozoides y los femeninos ovocitos.

Hay varios tipos principales de estolones: acéfalos (sin "cabeza") (Fig. 5 B), ácero (= Tetraglene) (una "cabeza" sin apéndices, y con dos pares de ojos) (Fig. $5 \mathrm{C}$ ), dícero (= Chaetosyllis) (una "cabeza" bilobulada con dos pares de ojos y dos antenas) (Fig. 5 D, E), tetrácero (una "cabeza" con dos palpos y dos antenas) (Fig. 5 F, G), pentácero (= Ioida) (una "cabeza" con dos pares de ojos, tres antenas y dos palpos) (Fig. $5 \mathrm{H}, \mathrm{I}$ ).

Los estolones de los Autolytinae tienen un marcado dimorfismo sexual. Los estolones masculinos (Polybostrichus) tienen una "cabeza" con dos pares de ojos, dos palpos bífidos y alargados, tres antenas, la central larga y espiralizada (Fig. 6 C). El estolón femenino (Sacconereis) tiene una "cabeza" con dos pares de ojos, dos palpos cortos y simples y tres antenas (Fig. 6 D, E). Ambos tienen dos pares de "cirros tentaculares".

También hay algunos casos de viviparismo en especies de las subfamilias Exogoninae Langerhans, 1879 y Syllinae Grube, 1850 (ver Simon et al. 2014).

Clave para las subfamilias y algunos géneros

"incertae sedis" de la familia Syllidae registrados en Chile

1a Cuerpo con un número pequeño y fijo de segmentos, más o menos romboidales, con el último segmento del cuerpo ápodo y aqueto, y con dos pares de cirros largos .................................... 2 1b Cuerpo con varios segmentos, variable según el tamaño, y el último segmento con parápodos y sedas

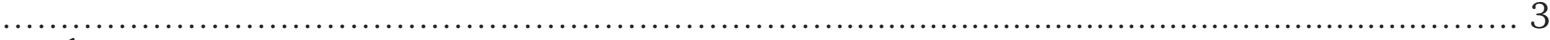
2a Órganos nucales en forma de proyecciones nucales; faringe larga y delgada, recurvada, con un trépano, sin diente medio dorsal (Fig. 7A-A')

Amblyosyllis

2b Órganos nucales en forma de hendiduras ciliadas; faringe recta, con un diente medio dorsal y un arco incompleto de unos pocos dentículos (Fig. 7B)

Brachysyllis 3a Cirros ventrales ausentes (posiblemente fusionados a los lóbulos parapodiales); faringe larga, delgada y con vueltas, armada de un trépano con dientes; reproducción por epigamia o esquizogamia

Subfamilia Autolytinae

3b Cirros ventrales presentes; faringe recta; reproducción variable según grupos ........................ 4

4a Faringe inerme; reproducción por epigamia o con incubación de huevos ventralmente

Subfamilia Anoplosyllinae

4b Faringe con diente medio dorsal, trépano o ambos .......................................... 5

5a Antenas, cirros tentaculares y cirros dorsales articulados (moniliformes), más o menos largos; reproducción típicamente por esquizogamia. ................................... Subfamilia Syllinae 5b Apéndices lisos o débilmente articulados en la parte anterior del cuerpo; reproducción por epigamia (desconocida en varios géneros) ................................................................. 6 6a Palpos fusionados totalmente o al menos hasta la mitad de su longitud; antenas, cirros tentaculares y dorsales cortos (a veces papiliformes); huevos incubados dorsalmente mediante notosedas capilares o 
ventralmente, sujetos a los nefridióporos

Subfamilia Exogoninae 6b Palpos no fusionados totalmente; apéndices largos, filiformes; reproducción por epigamia (o desconocida en algunos casos), sin incubación de huevos (con una excepción)

Subfamilia Eusyllinae (más algunos géneros incertae sedis)

Género Amblyosyllis Grube, 1857

Amblyosyllis Grube, 1857, p. 186

1. Amblyosyllis granosa Ehlers, 1897

Amblyosyllis granosa Ehlers, 1897, pp. 58-60, lám. 3, figss. 73-76.

Localidad tipo: Punta Arenas (5310’ S), estrecho de Magallanes.

Otras referencias para Chile: Ehlers (1901b, p. 100); Wesenberg-Lund (1962, p. 6263); Álvarez-Campos \& Verdes (2017, p. 4).

Localidades de registro en Chile: playa Las Cruces (3330' S, 71³9' O), Chile central (Álvarez-Campos \& Verdes, 2017). Canal de Chacao, O de Rocas Amazonas, 40 m; canal Dalcahue, $\mathrm{O}$ de Bajo Pasaje, intermareal (Lund University Chile Expedition St. M94:

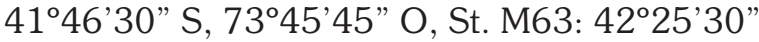
S, 73³9'20" O, Wesenberg-Lund 1962). Punta Arenas (53¹0' S), estrecho de Magallanes, $24 \mathrm{~m}$; canal Beagle (Ushuaia, 5449' S) , 18 m (Ehlers, 1897).

Distribución: Sudoeste de Australia; Nueva Zelanda, Auckland e islas Campbell; islas
Kerguelen; Tristan da Cunha (Westheide, 1974); Pacífico de Panamá; islas Galápagos (Capa et al. 2001); islas Georgias del Sur (Orensanz, 1976); Chile: playa Las Cruces, Chile central y desde el canal de Chacao hasta el canal Beagle.

\section{Género Brachysyllis}

Imajima \& Hartman, 1964

Brachysyllis Imajima \& Hartman, 1964, p. 108

\section{Brachysyllis infuscata (Ehlers, 1901)} 258-259.

Amblyosyllis infuscata Ehlers, 1901b, pp.

Brachysyllis infuscata: Imajima \& Hartman, 1964, p. 110; Aguado \& San Martín, 2008, p. 4043, figs. 3, 4.

Otras referencias para Chile: Soto \& San Martín, 2017, p. 5. 27-36 m

Localidad tipo: archipiélago Juan Fernández,

Distribución: Hasta ahora conocida sólo en la localidad tipo y en la región de Magallanes (canal Concepción, isla Drummond Hay, 50¹6’37' S, $\left.74^{\circ} 53^{\prime} 21^{\prime \prime} \mathrm{O}\right)$.

Clave para los géneros de la subfamilia Anoplosyllinae

Aguado \& San Martín, 2009 registrados en Chile

1a Todos los cirros dorsales son lisos y más o menos en forma de maza (Fig. 7C)

Anoplosyllis

1b Los cirros dorsales son articulados desde el setígero 3 (Fig. 7D)

Syllides

Género Anoplosyllis Claparède, 1868

Anoplosyllis Claparède, 1868, p. 524

\section{Anoplosyllis sexoculata}

(Hartmann-Schröder, 1962)

Syllides sexoculata Hartmann-Schröder,
1962, p. 97, figs. 78-80.

Anoplosyllis sexoculata: San Martín \& Hutchings, 2006, pp. 267-268, fig. 6.

Localidad tipo: Niebla (3952' S), Valdivia.

Distribución: Namibia, Australia: Victoria,

Nueva Gales del Sur; Chile: Niebla (3952’ S),

Valdivia. 


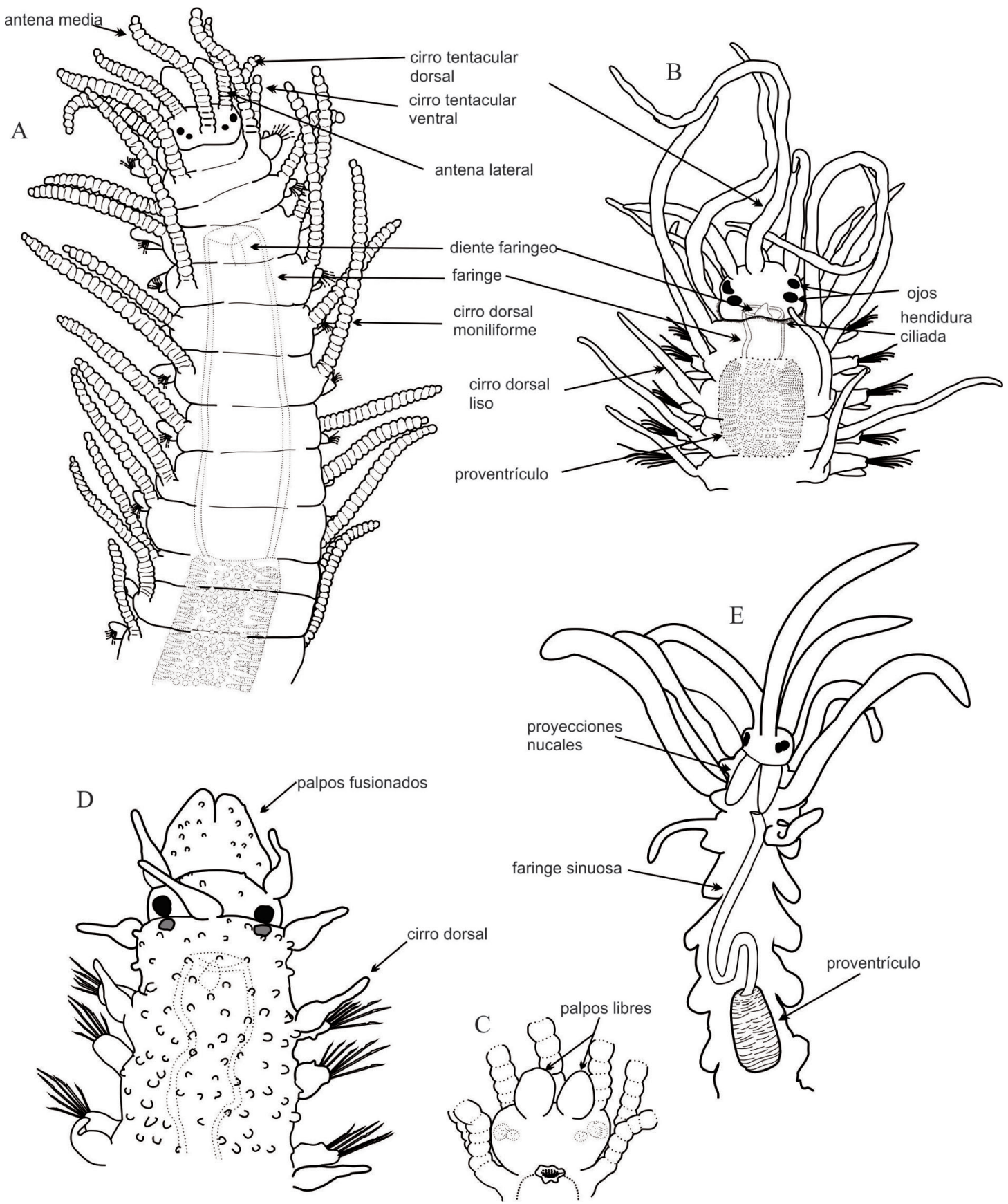

Fig. 2. Parte anterior de: A. Syllis amica (SF. Syllinae), cuerpo cilindrico, superficie lisa, dos pares de cirros tentaculares, antenas, cirros tentaculares y cirros dorsales moniliformes, órganos nucales en forma de hendiduras ciliadas, palpos fusionados en la base. B. Nudisyllis pulligera (SF. Eusyllinae), cuerpo cilindrico, superficie lisa, dos pares de cirros tentaculares, antenas, cirros tentaculares y dorsales lisos, órganos nucales en forma de hendiduras ciliadas, palpos libres. C, Trypanosyllis coeliaca (SF. Syllinae), prostomio en vista ventral mostrando los palpos libre. D, Sphaerosyllis pirifera (SF Exogoninae), cuerpo cilíndrico, superficie papilada, un solo par de cirros tentaculares, antenas, cirros tentaculares y dorsales lisos y cortos, órganos nucales en forma de hendiduras ciliadas, palpos totalmente fusionados. E, Proceraea enopla (SF. Autolytinae), cuerpo cilíndrico, superficie lisa, dos pares de cirros tentaculares, antenas, cirros tentaculares y dorsales lisos, proyecciones nucales, palpos totalmente fusionados, faringe larga y con numerosas vueltas (A-D, modificado de San Martín, 2003; E, modificado de Díaz-Díaz \& Ríos, 2015). 

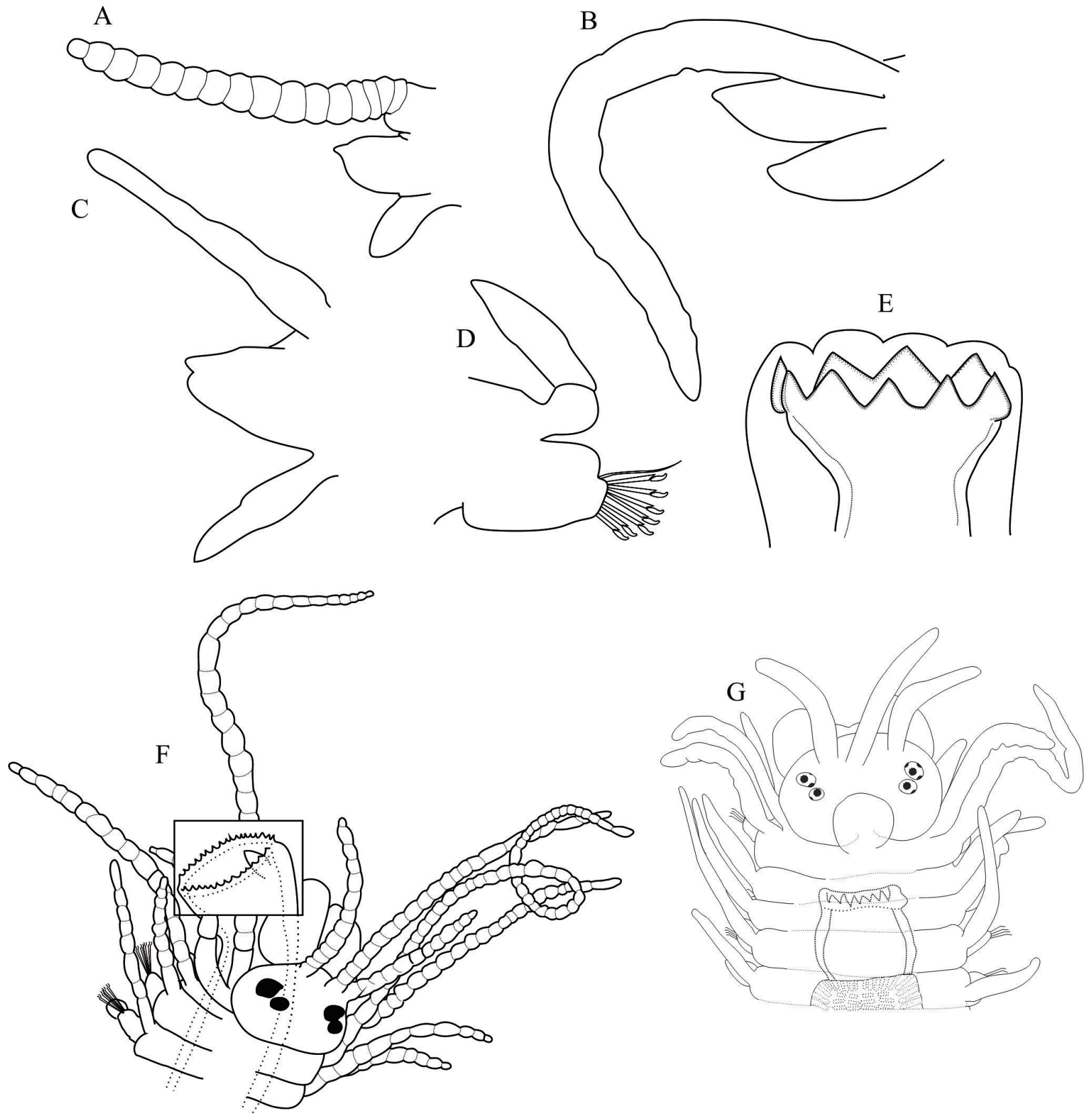

Fig. 3. Vista lateral de un parápodo de: A, Syllis amica, cirro dorsal moniliforme y largo. B, Nudisyllis pulligera, cirro dorsal liso y largo. C, Parapionosyllis brevicirra (SF. Exogoninae), cirro dorsal liso y corto. D, Epigamia labordai (SF. Autolytinae), cirro dorsal liso, corto, sin cirro ventral. E, trépano, sin diente faríngeo, de Myrianida convoluta (SF. Autolytinae). F, faringe evertida de Eusyllis assimilis (SF. Eusyllinae), mostrando un trépano incompleto y diente faríngeo. G, parte anterior de Odontosyllis fulgurans (SF. Eusyllinae), con un trépano incompleto y los dentículos dirigidos hacia la parte posterior del cuerpo (Modificado de San Martín, 2003). 
Género Syllides Ørsted, 1845

Syllides Ørsted, 1845b, pp. 408-409

Clave para las especies del Género Syllides registradas en Chile

1a Seda simple dorsal puntiaguda, con el extremo fino. Artejos de las sedas compuestas más largas con 1-3 espinas basales más largas que las restantes ..................... Syllides japonica Imajima, 1966 1b Seda simple dorsal con el extremo romo y redondeado, más gruesa que la de la especie anterior. Sedas compuestas sin espinas basales más largas que el resto

Syllides articulosa Ehlers, 1897

\section{Syllides articulosa Ehlers, 1897}

Syllides articulosus Ehlers, 1897, pp 4245, lám. 2, figs. 48-52.

Localidad tipo: Punta Arenas (5310’ S), estrecho de Magallanes.

Otras referencias para Chile: Ehlers, 1901b, p. 96); Wesenberg-Lund, 1962, p. 59 (sólo se cita); Hartmann-Schröder, 1965, pp. 111, 113, 114, 291, figs. 71-73; Soto \& San Martín, 2017, p. 6, Figs. 5C, D.

Localidades de registro en Chile: punta Galera, $84 \mathrm{~m}$ (Expedición MarChile I St. 93: 3958' S, 7344,8' O); Pelluco, E de la ciudad de Puerto Montt; bahía de Ancud, puerto Inglés, 12 m (Hartmann-Schröder, 1965). Punta Arenas (5310' S), estrecho de Magallanes; canal Beagle (Ushuaia, 5449' S) (Ehlers, 1897). Región de Magallanes (Soto \& San Martín, 2017).

Distribución: islas Falkland (Malvinas); sur de Argentina; islas subantárticas; Antártida
(Hartmann-Schröder \& Rosenfeldt, 1988); Chile, desde punta Galera (39 58' S) hasta el canal Beagle (54²9' S).

\section{Syllides japonica Imajima, 1966}

Syllides japonicus Imajima, 1966a, pp. 112-114, lám. 36.

Localidad tipo: Funadomari, isla Rebun, y Kutsugata, isla Rishiri, al NO de la isla de Hokkaido, Japón.

Referencia para Chile: Soto \& San Martín, 2017, pp. 5-6, Figs. 5A, B.

Localidades de registro en Chile: región de Magallanes, canal Concepción, isla Drummond (50¹6'37' S, 7453'21' O); canal Ballenero (5457`30.9" S, 7044`41.0” O).

Distribución: Japón; cabo Cod (Massachusetts, USA); isla López (Washington, USA); Mediterráneo occidental; NO península Ibérica; Australia; Chile.

Subfamilia Autolytinae Langerhans, 1879

Clave para los géneros de la subfamilia Autolytinae registrados en Chile

1a Reproducción por epigamia

Epigamia

1b Reproducción por esquizogamia 2

2a Sedas en bayoneta de tipo estrecho, delgadas (Fig. 7E); reproducción por gemiparidad

Myrianida

2b Sedas en bayoneta de tipo ancho, ensanchadas en el extremo (Fig. 7F); reproducción por escisiparidad anterior

Proceraea

La especie Autolytus longstaffi (Ehlers, 1912) fue considerada por Nygren (2004) como una especie dudosa, de la que no hay descripciones adecuadas y cuyo material tipo no existe; no se incluye en las claves, al igual que Autolytus gibber
Ehlers, 1897, que es considerada por el mismo autor en la sinonimia de Epigamia (?) maclearanus (McIntosh, 1855).

Parautolytus fasciatus Ehlers, 1900 es un taxón no válido, puesto que sus caracteres no 
están bien conocidos, no existe la serie tipo y la descripción es incompleta.

Género Epigamia Nygren, 2004

Epigamia Nygren, 2004, p. 163

Las dos únicas especies de este género registradas en Chile fueron descritas en áreas antárticas: Epigamia charcoti (Gravier, 1906), y Epigamia (?) maclearanus (McIntosh, 1885), especie cuyos caracteres no son bien conocidos y que incluso su pertenencia a este género es dudosa.

\section{Epigamia charcoti (Gravier, 1906)}

Autolytus charcoti Gravier, 1906, pp. 7-8, lám.1, figs.1-2, textfigs.1-2.

Epigamia charcoti: Nygren, 2004, pp. 169, figs. 85 A-E.

Localidad tipo: península Antártica, bahía Carthago, puerto Charcot, $40 \mathrm{~m}$.

Referencias para Chile: Wesenberg-Lund, 1962, p. 67; Gambi y Mariani, 1999, p. 237 (sólo se cita); Bremec, Elías y Gambi, 2000, pp. 194 (sólo se cita).

Localidades de registro en Chile: bahía de Ancud, península Lacui, punta Corona, intermareal; archipiélago de los Chonos, canal Moraleda. puerto Lagunas, 0-7 m (Lund University Chile Expedition St. M56: 41 $47^{\prime}$ S, 7353'07' O, St. M74: 4517' S, 7345' O, Wesenberg-Lund 1962). Estrecho de Magallanes (5252' S, 70³2' O), 70-80 m (Gambi \& Mariani, 1999).

Distribución: Sudáfrica; Nueva Zelanda; islas Falkland (Malvinas); islas subantárticas; Antártida (Hartmann-Schröder \& Rosenfeldt, 1988); Chile: desde bahía de Ancud (41⒋ $\left.47^{\prime} \mathrm{S}\right)$ hasta el estrecho de Magallanes (52 $52^{\prime} \mathrm{S}$ ).

\section{Epigamia (?) maclearanus}

(McIntosh, 1885)

Autolytus maclearanus McIntosh, 1885, p. 207-208, lám. 29, fig. 6, lám. 33, fig. 5, lám. 15A, fig. 15.

Epigamia Incertae sedis: Autolytus maclearanus Nygren, 2004, pp. 180-181, figs.
92 A-E.

Localidad tipo: islas Kerguelen, frente a Greenland Harbour (49³7' S, 70¹6' E), 54 m.

Referencia para Chile: Autolytus (Polybostrichus) maclearamus: WesenbergLund, 1962, p. 68, fig. 21.

Localidades de registro en Chile: golfo de Ancud, estero Huito, N de punta Yahuecha, 35 $\mathrm{m}$ (Lund University Chile Expedition St. M18: 41 45'30" S, 7307'50" O, Wesenberg-Lund 1962).

Distribución: región subantártica; islas Kerguelen; islas Chatham (Day, 1967); Antártida (Orensanz, 1976); Chile: golfo de Ancud (4145'30” S).

Género Myrianida Milne Edwards, 1845

Myrianida Milne Edwards, 1845, p. 180.

\section{Myrianida (?) simplex (Ehlers, 1900)}

Autolytus simplex Ehlers, 1900, p. 213.

Myrianida Incertae sedis: Autolytus simplex Nygren, 2004, p. 162.

Es la única especie de este género que podría considerarse reportada en aguas chilenas, aunque sus caracteres son mal conocidos y no existen los tipos.

Localidad tipo: bahía Harris (5352’ S), estrecho de Magallanes.

Otras referencias para Chile: Ehlers, 1901b, pp. 97-98, lám. 10, figs. 5-8; Augener, 1922, pp. 190-191; Hartman: 1964, pp. 78-79, lám. 24, figs. 6-7, 1967, pp. 54 (sólo se cita); Wesenberg-Lund, 1962, p. 66.

Localidades de registro a lo largo de la costa de Chile y el archipiélago Juan Fernández: Montemar, N de Valparaíso, "Estación de Biología Marina", intermareal; seno Reloncaví, al E de punta Ilque, $390 \mathrm{~m}$ (Lund University Chile Expedition St. M123: 3257'24” S, 71'33'25"

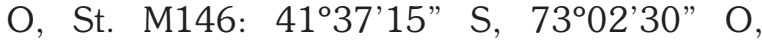
Wesenberg-Lund 1962). Bahía Harris (5352' S), isla Dawson, estrecho de Magallanes (Ehlers, 1900). Estrecho de Magallanes, paso del Hambre (USNS Eltanin St. 963: 53⒋ a 534' S, 7053' O, Hartman 1967). Archipiélago Juan Fernández, isla Robinson Crusoe, 30-45 m (Augener, 1922). 
Distribución: islas Falkland (Malvinas); islas Shetland del Sur; estrecho Bransfield; península Antártica; Dorsal Pacífico-Antártica (Hartman, 1967); isla South Georgia (Hartman, 1964); Chile: desde Valparaíso (32 57'24” S) hasta el estrecho de Magallanes (5348' S) y archipiélago Juan Fernández, isla Robinson Crusoe.

Género Proceraea Ehlers, 1864

Proceraea (Ehlers, 1864, p. 256)

\section{Proceraea micropedata}

(Hartmann-Schröder, 1965)

Odontosyllis micropedata HartmannSchröder, 1962, pp. 100-103, figs. 87-92.

Proceraea micropedata Nygren, 2004, p. 58, figs. 16 A-C.

Esta es la única especie del género que se ha registrado en Chile.

Localidad tipo: desembocadura del río Andalién (3640’ S), bahía de Concepción.
Orensanz (1976) transfirió la especie Odontosyllis micropedata al género Proceraea Ehlers, 1864.

Otras referencias para Chile: HartmannSchröder: 1965, p. 122; Palma et al. 2005, p. 240; Álvarez-Campos y Verdes, 2017, p. 4.

Localidades de registro en Chile: playa

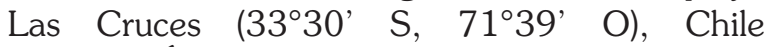
central (Álvarez-Campos \& Verdes, 2017). Desembocadura del río Andalién (36 $40^{\prime}$ S), bahía de Concepción; Coronel ( $\left.37^{\circ} 01^{\prime} \mathrm{S}\right)$, golfo de Arauco; punta Carreras (53 $36^{\circ}$ S), estrecho de Magallanes (Hartmann-Schröder, 1962). Punta Lavapié, 58 m (Expedición MarChile I St. 68: $37^{\circ} 08,7^{\prime}$ S, $73^{\circ} 38,6^{\prime}$ O, Hartmann-Schröder, 1965). Concepción (PUCK Expedition St. 7160: 3602'35 S, 7304'40" O, $365 \mathrm{~m}$, St. 7166: $36^{\circ} 27^{\prime} 99 \mathrm{~S}, 73^{\circ} 46^{\prime} 47 \mathrm{O}, 1294 \mathrm{~m}$, Palma et al. 2005).

Distribución: Hasta ahora conocida sólo en Chile, desde playa Las Cruces (33 $30^{\circ}$ S) hasta el estrecho de Magallanes (53³6’ S).

\section{Subfamilia Eusyllinae Malaquin, 1893}

Clave para los géneros de la subfamilia Eusyllinae registrados en Chile, y algunos géneros "Incertae sedis"

1a Diente faríngeo ausente; faringe con un trépano incompleto formado por pocos dentículos dirigidos hacia la parte posterior del cuerpo (Fig. $3 \mathrm{G}$ ) Odontosyllis $1 \mathrm{~b}$ Diente faringeo presente ................................................................... 2 2a Faringe con diente medio dorsal y un trépano incompleto de pequeños dentículos dirigidos hacia la parte anterior del cuerpo (Fig. $3 \mathrm{~F}$ ) Eusyllis

$2 \mathrm{~b}$ Faringe sin trépano, solamente con el diente faríngeo medio dorsal 3 3a Cuerpo diminuto, de vida estrictamente intersticial en arenas; palpos de apariencia biarticulados; antenas, cirros tentaculares y los cirros dorsales del primer setígero son largos, los restantes son muy cortos (Fig. 9 A) ....

Neopetitia

3b Cuerpo de mayor tamaño; palpos sin apariencia biarticulada; apéndices largos ..................... 4 4a Antenas y cirros anteriores más o menos articulados, lisos los restantes; con una papila subcirral digitiforme, muy difícil de ver, bajo las bases de los cirros dorsales (Fig. 9 B)

Paraehlersia

4b Todos los apéndices son lisos (pueden aparecer rugosos tras la fijación); sin papila subcirral ........ 5 5 a Palpos casi totalmente separados; bandas ciliares en cada segmento; sedas compuestas con artejos largos, pseudospinígeras y falcígeras, con espinas en el margen muy largas

5b Palpos claramente fusionados en la base; sin bandas ciliares; sedas compuestas sin pseudospinígeras, y sin espinas largas en el margen

Pionosyllis (Fig. 9 D) 
Género Eusyllis Malmgren, 1867

Eusyllis Malmgren, 1867b, p. 159

\section{Eusyllis nuchalata}

Hartmann-Schröder, 1965

Eusyllis nuchalata Hartmann-Schröder, 1965, pp. 115-118, figs. 76-79. $58 \mathrm{~m}$.

Localidad tipo: punta Lavapié ( $37^{\circ} 08,7^{\prime}$ S),

Localidades de registro en Chile: punta Lavapié, $58 \mathrm{~m}$; golfo Corcovado, al E de la isla Puduhuapi, 190 m (Expedición MarChile I St. 68:

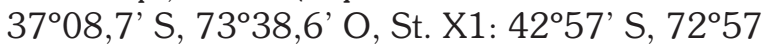
O, Hartmann-Schröder, 1965). La especie fue redescrita por Brusa et al. (2013) sobre el material tipo.

Distribución: hasta ahora conocida sólo en Chile, en punta Lavapié $\left(37^{\circ} 08,7^{\prime}\right.$ S) y el golfo Corcovado (4257' S).

Género Neopetitia San Martín, 2003

Neopetitia San Martín, 2003, p. 49.

\section{Neopetitia amphophthalma}

(Siewing, 1955)

Petitia amphophthalma Siewing, 1955, pp. 414-423, figs. 1-8.

Neopetitia amphophthalma: San Martín, 2003, pp. 49-51, figs. 12.

Localidad tipo: golfo de Gascuña.

Referencia para Chile: Petitia amphophthalma: Hartmann-Schröder (1965, pp. 291-292).

Localidades de registro en Chile: Arica

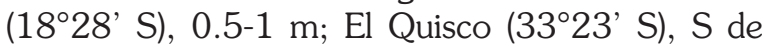
Algarrobo; desembocadura de la quebrada de Cordova (3326' S), al N de El Tabo (HartmannSchröder, 1965).

Distribución: mar Mediterráneo; mar Rojo; Atlántico (Frankreich, islas Bimini); costa de Marfil (Laubier, 1967); Perú (Hartmann-Schröder, 1965); Chile, en Arica ( $18^{\circ} 28^{\prime}$ S) y la quebrada de Córdova (33²6' S), al N de El Tabo.

$\mathrm{Al}$ igual que con otras especies de las costas europeas, la especie registrada en Chile podría corresponder a otra especie diferente.
Género Odontosyllis Claparède, 1863

Odontosyllis Claparède, 1863, p. 47

\section{Odontosyllis magnanuchalata}

Hartmann-Schröder, 1965

Odontosyllis magnanuchalata HartmannSchröder, 1965, pp. 122-124, figs. 84-87.

Localidad tipo: golfo Corcovado, al E de la isla Puduhuapi (Expedición MarChile I St. X1: 42 $57^{\prime} \mathrm{S}, 72^{\circ} 57^{\prime} \mathrm{O}$ ), $190 \mathrm{~m}$.

Distribución: Hasta ahora conocida sólo en Chile en la localidad tipo, golfo Corcovado.

Género Paraehlersia San Martín, 2003

Paraehlersia San Martín, 2003, p. 61.

\section{Paraehlersia ferrugina}

(Langerhans, 1881), como Ehlersia ferrugina.

Ehlersia ferrugina Langerhans, 1881, pp. 104-105, lám. 4, fig. 10 a-b.

Paraehlersia ferrugina: San Martín, 2003, pp. 61-65, figs. 19-21.

Localidad tipo: islas Canarias.

Referencia para isla de Pascua: Syllis (Langerhansia) ferrugina: Kohn y Lloyd: 1973, p. 694.

Localidad de registro en isla de Pascua: entre bahía Hanga-Roa y Hanga-Piko, en poza de marea (Kohn \& Lloyd, 1973).

Distribución: Irlanda; mar Mediterráneo; islas Canarias; de Angola a Sudáfrica; Carolina del Norte; Chile: isla de Pascua.

La presencia de $P$. ferrugina en isla de Pascua es altamente dudosa y probablemente se trata de alguna otra especie.

\section{Paraehlersia kawesqar}

Soto \& San Martín, 2017

Paraehlersia kawesqar Soto \& San Martín, 2017, pp. 2-4, figs. 1-4.

Localidad tipo: región de Magallanes, canal Concepción, isla Drummond Hay, 50¹6'37' S 745'21" O.

Distribución: hasta ahora conocida sólo en la localidad tipo, región de Magallanes. 


\section{Género Perkinsyllis}

San Martín, López y Aguado, 2009

Perkinsyllis San Martín et al. 2009, p. 1479

\section{Perkinsyllis longisetosa}

(Hartmann-Schröder, 1965)

Pionosyllis longisetosa Hartmann-Schröder, 1965, pp. 118-120, figs. 80-83.

Perkinsyllis longisetosa: San Martín et al. 2009, pp. 1480-1481, fig. 8.

Localidad tipo: cabo Quedal (4054'S), 176 m.

Localidades de registro en Chile: punta Lavapié, $58 \mathrm{~m}$; NE de la isla Mocha, frente a punta Nena, 26 m; punta Galera, 162-260 m; cabo Quedal, 176 m (Expedición MarChile I St. 68: 3708,7’ S, 73³8,6' O, St. 75: 38¹5,9' S, 73³3' O, St. 95: 3959' S, 7354,5' O, St. 96: 3959,9' S, 7401,5' O, St. 107: $40^{\circ} 54^{\prime}$ S, $74^{\circ} 04,1^{\prime}$ O, HartmannSchröder, 1965).

Distribución: hasta ahora conocida sólo en Chile, desde punta Lavapié (3708,7' S) hasta cabo Quedal (4054' S).

Género Pionosyllis Malmgren, 1867

Pionosyllis Malmgren, 1867b, p. 158

\section{Pionosyllis kerguelensis}

(McIntosh, 1885)

Eusyllis kerguelensis McIntosh, 1885, pp. 191-192, lám. 29, fig. 4, lám. 33, fig. 3, lám. 15A, fig. 13.

Pionosyllis kerguelensis: San Martín \& Parapar, 1997, p. 291; San Martín \& Hutchings, 2006, p. 337, fig. 66 A-F; San Martín et al. 2009, pp. 1487-1489 (revisión del material tipo).

Localidad tipo: islas Kerguelen, frente a Christmas Harbour (4845’ S, 69¹4' E), 232 $\mathrm{m}$.

Referencias para Chile: Eusyllis kerguelensis: Ehlers 1897, p. 42; 1900, p. 212; 1901b, p. 96; Wesenberg-Lund, 1962, pp. 59-60, fig. 19; Hartman, 1964, p. 81, lám. 25, figs. 2-3; Hartmann-Schröder, 1965, p. 115, figs. 74-75.

Localidades de registro en Chile: al NE de la isla Mocha, frente a punta Nena, 26 m (Expedición MarChile I St. 75: 38¹5,9' S, 73³3' O, Hartmann-Schröder, 1965). Archipiélago de Chiloé, paso Tenaun, S de punta Tenaun, $70 \mathrm{~m}$ (Lund University Chile Expedition St. M42: 42²0'50” S, 73²2' O,

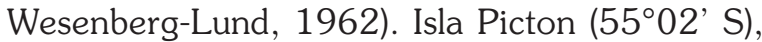
punta Nordeste, $7 \mathrm{~m}$ (Ehlers, 1897). Isla Lennox (55¹8' S), caleta Lennox, 18-45 m (Ehlers, 1900).

Distribución: Nueva Zelanda; Australia; islas Falkland (Malvinas); islas subantárticas; Antártida (Hartmann-Schröder \& Rosenfeldt, 1988); Chile: desde frente a isla Mocha (38 $15,9^{\prime}$

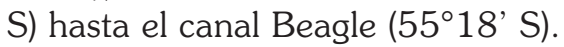

Subfamilia Exogoninae Langerhans, 1879

Clave para los géneros de la subfamilia Exogoninae registrados en Chile

(Basada en caracteres reproductores y morfológicos)

1a Hembras incuban dorsalmente 2

$1 \mathrm{~b}$ Hembras incuban ventralmente, y se desarrollan juveniles 4

2a Con dos pares de cirros tentaculares; cuerpo liso, sin papilas (Fig. 8 B) . . Salvatoria

$2 \mathrm{~b}$ Con un solo par de cirros tentaculares; cuerpo con papilas 3 3a Algunos cirros dorsales con cirrostilo retráctil; antenas cortas; faringe relativamente larga y ancha; diente faríngeo localizado por regla general alejado del margen anterior; sedas compuestas con artejos cortos y unidentados Prosphaerosyllis 3b Antenas y cirros dorsales más o menos alargados, sin cirrostilo retráctil; faringe relativamente delgada; diente faríngeo situado cerca del margen anterior; sedas compuestas con artejos alargados, bidentados, unidentados y bidentados o solamente unidentados (Fig. $8 \mathrm{G}$ ) 
5 a Con dos pares de cirros tentaculares

Brania

56 Con un par de cirros tentaculares

6

6a Palpos fusionados basalmente desde la mitad a 2/3 de su longitud; cirros dorsales en forma de bolo; glándulas parapodiales bien definidas (Fig. $8 \mathrm{C}$ )....

Parapionosyllis

6b Palpos totalmente fusionados o casi totalmente; cirros dorsales muy pequeños, papiliformes; glándulas

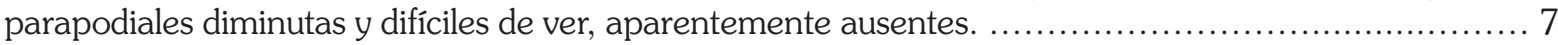
7a Sedas compuestas con artejos falcígeros bidentados, con los dos dientes similares y, en algunas especies, con algunas sedas de artejos alargados, similares a las falcígeras, pero más largas y delgadas

Parexogone $7 b$ Sedas compuestas muy diferentes, algunas con artejos muy finos, en forma de espinígeras, y el resto falcígeras con artejos muy cortos, bidentados, con el diente proximal claramente mayor que el distal

Exogone

Aunque el género Brania ha sido citado en las costas chilenas en varias ocasiones, parece que realmente se refieren a especies del género Salvatoria. Sin embargo, lo hemos incluido en las claves, porque su presencia en el mar de Chile es muy probable.

Clave para los géneros de la subfamilia Exogoninae registrados en Chile

(Basada exclusivamente en caracteres morfológicos)

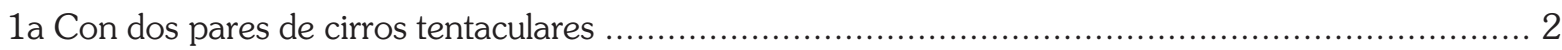

1b Con un solo par de cirros tentaculares ............................................................... 3

2a Palpos fusionados basalmente desde la mitad a 2/3 de su longitud; cirros dorsales en forma de bolo; glándulas parapodiales bien visibles; acículas distalmente redondeadas; faringe delgada; diente faríngeo cónico, situado en la embocadura faríngea (Fig. 8 A) ......................................... Brania 2b Palpos unidos mediante una membrana dorsal; cirros dorsales fusiformes, más o menos alargados; sin glándulas parapodiales; acículas acuminadas; faringe y proventrículo largos y anchos; diente faríngeo romboidal a ovalado, situado generalmente algo alejado de la embocadura faríngea (Fig. 8 B) .. Salvatoria

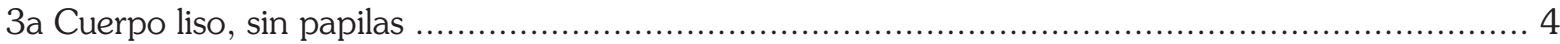

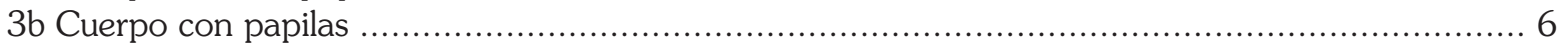

4a Palpos fusionados basalmente desde la mitad a 2/3 de su longitud; cirros dorsales en forma de bolo; glándulas parapodiales bien visibles; seda simple dorsal aserrada (Fig. $8 \mathrm{C}$ ) ............... Parapionosyllis 4b Palpos completamente fusionados o casi; cirros dorsales pequeños, papiliformes; glándulas parapodiales no visibles o diminutas; sedas simples dorsales diferentes ................................ 5 5a Sedas compuestas con artejos falcígeros bidentados, con los dos dientes similares y, en algunas especies, con algunas sedas de artejos alargados, similares a las falcígeras, pero más largas y delgadas (Fig. 8 D)

Parexogone

$5 b$ Sedas compuestas muy diferentes, algunas con artejos muy finos, en forma de espinígeras, y el resto falcígeras con artejos muy cortos, bidentados, con el diente proximal claramente mayor que el distal (Fig. $8 \mathrm{E})$

Exogone

6a Prostomio con 4 ojos, sin manchas oculares; proventrículo corto, con pocas bandas musculares, anchas; faringe delgada; diente faríngeo pequeño, cónico, situado en la parte anterior de la faringe; antenas y cirros dorsales con forma de cebolla; acículas con la punta formando un ángulo recto (Fig. 2 E) .........

\section{Sphaerosyllis}

6b Prostomio con 4 ojos y 2 manchas oculares anteriores (alguna especie sin ojos ni manchas oculares); proventrículo con forma de barril, relativamente ancho y largo, con numerosas bandas musculares delgadas; faringe relativamente ancha; acículas acuminadas ............................................ 7 7a Faringe claramente ancha; diente faringeo romboidal a oval, largo, situado generalmente lejos del margen anterior faríngeo; antenas y cirros dorsales similares a los de Sphaerosyllis, típicamente con un 
cirróforo alargado y un cirrostilo retráctil; sedas compuestas con artejos falcígeros cortos y unidentados (Fig. 8 F) Prosphaerosyllis

7b Faringe proporcionalmente más alargada, no tan ancha; diente faríngeo pequeño, situado cerca del margen anterior; antenas y cirros dorsales algo alargados, a veces parecidos a los de Sphaerosyllis, siempre sin cirrostilos; sedas compuestas con artejos alargados, generalmente, bidentados, unidentados y bidentados, o unidentados (Fig. $8 \mathrm{G}$ )

Erinaceusyllis

Género Erinaceusyllis San Martín, 2005

Erinaceusyllis San Martín, 2005, p. 73

Dos especies registradas en Chile podrían pertenecer a este género: Parapionosyllis paucicirra papillata Hartmann-Schröder, 1962 y Sphaerosyllis subterranea Hartmann-Schröder, 1965, sin embargo sus descripciones son tan incompletas que no se puede afirmar con exactitud la pertenencia de dichas especies a este género, si bien parece que así sea. Además, recientemente se ha reportado $E$. bidentata y se ha descrito una especie nueva, E. carrascoi https://www.youtube. com/watch? $v=q o W R s 7 l X t Y E$ Soto et al. (en prensa).

\section{Erinaceusyllis bidentata}

(Hartmann-Schröder, 1974)

Sphaerosyllis erinaceus bidentata Hartmann-Schröder, 1974, p. 134-135, lám. 13, figs. 116-119.

Erinaceusyllis bidentata: San Martín, 2005, p. 77, fig. 31.

Localidad tipo: Luanda (Mozambique). prensa).

Referencias para Chile: Soto et al. (en

Localidad de registro en Chile: región de Magallanes.

Distribución: Mozambique; Australia; Chile: región de Magallanes.

\section{Erinaceusyllis carrascoi}

Soto, San Martín \& Peñaloza, en prensa

Erinaceusyllis carrascoi Soto, San Martín y Peñaloza, en prensa.

Localidad tipo: región de Magallanes (canal Concepción, isla Drummond Hay, 50¹6'37' S 7453'21" O; canal Ballenero, 5457’30.9” S 704441.0" O).
Distribución: hasta ahora sólo conocida en la localidad tipo, en la región de Magallanes.

\section{Erinaceusyllis (?) paucicirra papillata} (Hartmann-Schröder, 1962) n. comb.

Parapionosyllis paucicirra papillata Hartmann-Schröder, 1962, pp. 99-100, figs. 8486.

Localidad tipo: San Julián, Argentina.

Referencia para Chile: Hartmann-Schröder 1965, pp. 120-122.

Localidad de registro en Chile: punta Lavapié, 58 m (Expedición MarChile I St. 68: 3708,7' S, 73³8,6' O, Hartmann-Schröder, 1965).

Distribución: Argentina (San Julián) y Chile (punta Lavapié).

\section{Erinaceusyllis perspicax (Ehlers, 1908)}

Sphaerosyllis perspicax Ehlers, 1908, pp. 66-67, lám. 6, figs. 1-3.

Localidad tipo: islas Kerguelen.

Localidad de registro en Chile: región de Magallanes, canal Ballenero, 5457`30.9” S 7044־41.0" O.

Distribución: islas Kerguelen; Antártida; Chile: región de Magallanes.

\section{Erinaceusyllis (?) subterranea} (Hartmann-Schröder, 1965) n. comb.

Sphaerosyllis subterranea Hartmann-Schröder, 1965: 293-295, figs. 293-295.

Localidad tipo: norte de Chile, Arica (18 $\left.28^{\prime} \mathrm{S}\right)$, $0.5 \mathrm{~m}$.

Otra localidad de registro en Chile: Taltal $\left(25^{\circ} 25^{\prime}\right.$ S), 0.5 m (Hartmann-Schröder, 1965).

Distribución: Hasta ahora conocida solo en Chile, en Arica (18 $28^{\prime}$ S) y Taltal $\left(25^{\circ} 25^{\prime}\right.$ S). 

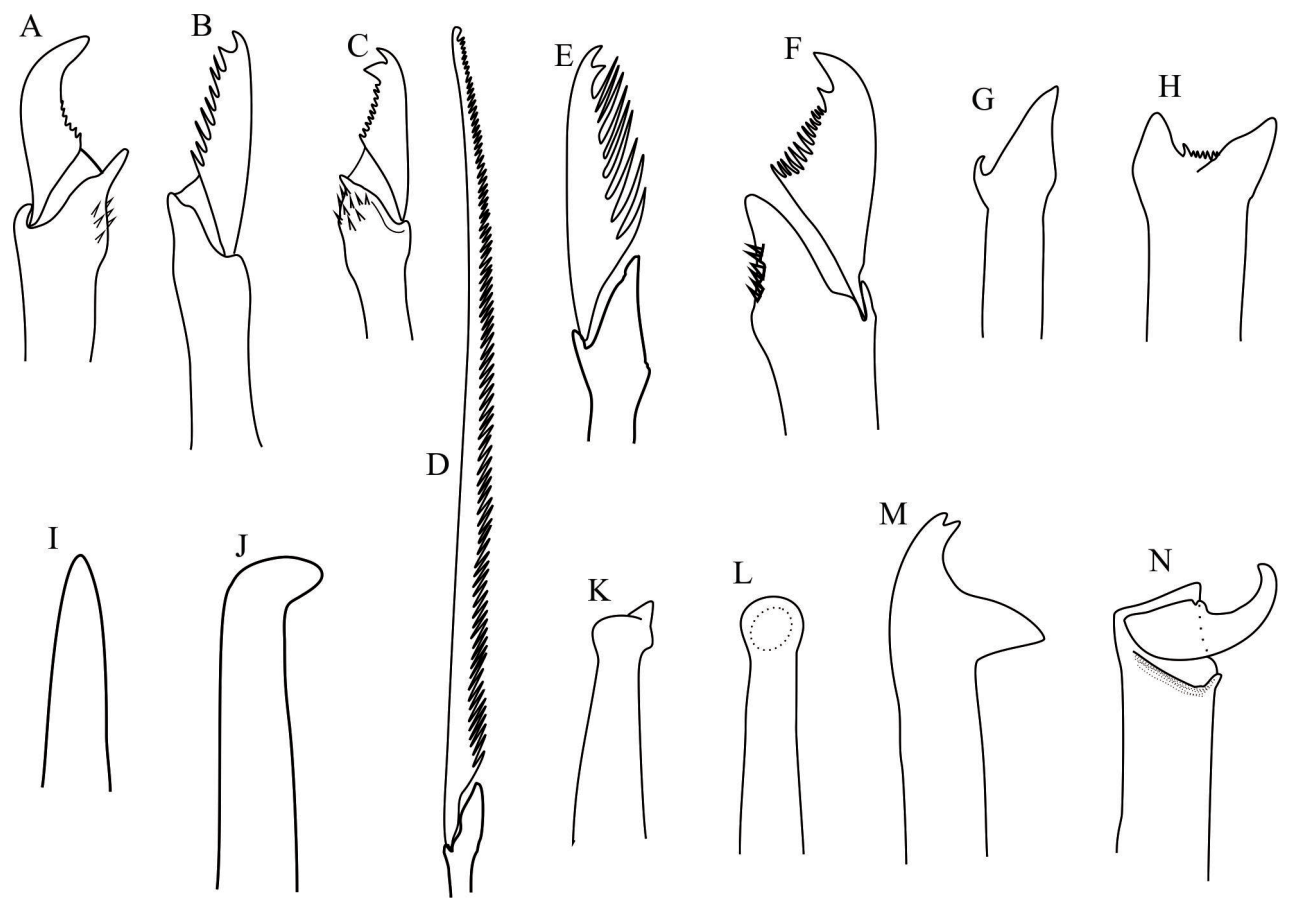

Fig. 4. Sedas compuestas de A, Sphaerosyllis pirifera (falcígera, unidentada, casi lisa en el margen); B, Trypanosyllis coeliaca (falcígera, bidentada con ambos dientes similares, espinas moderadas en el margen); C, Eusyllis assimilis (falcígera, bidentada, diente proximal mayor que el distal, espinas cortas en el margen); D, Syllis garciai (pseudo-espinígera, espinas largas en el margen); E, Syllis garciai (falcígera, bidentada, ambos dientes similares, espinas largas en el margen); F, Syllis krohnii (falcígera, bidentada, diente proximal menor que el distal, espinas cortas en el margen); G, Syllis amica (gruesa seda pseudosimple por pérdida del artejo y engrosamiento del mango); H, Syllis gracilis (gruesa seda pseudosimple por fusión del mango y artejo). Acícula de: I, T. coeliaca (recta y puntiaguda); J, E. assimilis (distalmente doblada en ángulo recto); K, S. gracilis (acuminada); L, Syllis prolifera (distalmente redondeada); M) Haplosyllis, seda simple; N) Branchiosyllis spp. en forma de garra curvada (úngulas) (Modificado de San Martín, 2003)

Género Exogone Ørsted, 1845

Exogone Ørsted, 1845a, p. 20

Clave para las especies del género Exogone registradas en Chile

1a Sin sedas pseudoespinígeras, solamente falcígeras, algunas ligeramente alargadas

Exogone yagan Soto, San Martín \& Peñaloza, en prensa

$1 \mathrm{~b}$ Con sedas pseudoespinígeras, claramente diferente a las falcígeras ....

2a Extremo de los mangos de las sedas pseudoespinígeras ensanchado y espinoso; artejos de esas sedas relativamente cortos y triangulares

2b Mangos no tan ensanchados ni tan espinosos; artejos de las sedas pseudoespinígeras delgados, filiformes

E. verugera (Claparède, 1868) 3a Antenas insertas cerca del margen posterior del prostomio; antena media fusiforme, claramente más larga que las laterales, de tamaño igual o superior a la longitud del prostomio mas los palpos

E. heterosetosa McIntosh, 1885

$3 \mathrm{~b}$ Antenas insertas cerca del margen anterior del prostomio; antena media en forma de bolo, ligeramente más larga que las laterales, de menor tamaño que la longitud del prostomio mas los palpos

E. heterosetoides Hartmann-Schröder, 1979 


\section{Exogone heterosetoides}

Hartmann-Schröder, 1979

Exogone heterosetoides HartmannSchröder, 1979, p. 110, figs. 171-174.

Localidad tipo: Broome (Australia).

Referencia para Chile: Soto et al. (en prensa).

Localidad de registro en Chile: región de Magallanes.

Distribución: Australia; Chile: región de Magallanes.

23. Exogone heterosetosa McIntosh, 1885

Exogone heterosetosa McIntosh, 1885, pp. 205-206, lám. 33, figs. 15-16, lám. 24A, fig. 11.

Localidad tipo: frente a la isla Marion (4648' S, 3749'30”E), 126 m.

Referencias para Chile: Ehlers, 1897, pp. 51-53, lám. 3, figs. 61-65; 1901b, p. 97; Fauvel, 1936, p. 20; Hartman, 1953, p. 25-26; 1964, pp. 81-82, lám. 25, figs. 4-5; Wesenberg-Lund (1962, pp. 65-66); Hartmann-Schröder, 1965, p. 127, fig. 92.

Localidades de registro en Chile: seno Reloncaví, frente a Puerto Montt, 30 m; golfo de Ancud, SO de isla Tabón, 200 m; entre el golfo de Ancud y el golfo Corcovado, ESE de isla Tac, 250-300 m (Lund University Chile Expedition

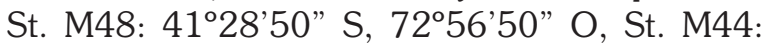

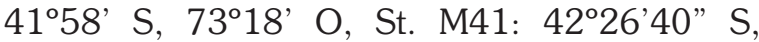
$72^{\circ} 59^{\prime}$ O, Wesenberg-Lund, 1962). Entre el golfo de Ancud y el golfo Corcovado, ESE de isla Tac, $240 \mathrm{~m}$ (Expedición MarChile I St. X2: 42 ${ }^{\circ} 4^{\prime}$ S, 7257' O, Hartmann-Schröder, 1965). Puerto Bueno $\left(50^{\circ} 59^{\prime} \mathrm{S}\right)$, canal Sarmiento, E de isla Esperanza, $14 \mathrm{~m}$; canal Beagle (Ushuaia, 54 ${ }^{\circ} 49^{\prime}$ S), $1,8-9 \mathrm{~m}$ (Ehlers, 1897). Canal O'Brien (= canal Francés) (5453' S), isla Londonderry (Fauvel, 1936). Ribera $\mathrm{N}$ del canal Beagle, entre Ushuaia y Lapataia (Swedish Antarctic Expedition St. 64:

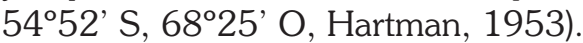

Distribución: sur de Australia; Nueva Zelanda; sur de Argentina; islas Falkland (Malvinas); islas subantárticas; Antártida (Hartmann-Schröder \& Rosenfeldt, 1988); Chile: desde el seno Reloncaví

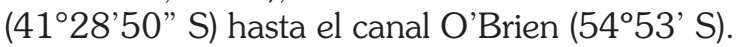

24. Exogone verugera (Claparède, 1868)

Paedophylax veruger Claparède, 1868, pp. 523-524, lám. 12, fig. 3.

Exogone verugera, Fauvel, 1923, pp. 307308, figs. $117 \mathrm{~m}$-r.

Localidad tipo: golfo de Nápoles.

Referencia para Chile: isla de Pascua (Kohn \& Lloyd, 1973, p. 696).

Localidad de registro en isla de Pascua: entre bahía Hanga-Roa y Hanga-Piko, en poza de marea (Kohn \& Lloyd, 1973).

Distribución: oeste de Groenlandia; Faroes; mar del Norte; Skagerrak a Oresund; mar Negro; mar Mediterráneo; Madeira; desde el golfo de St. Lawrence a Carolina del Norte; isla Vancouver; México; norte del mar de Japón a Japón; Australia; península Antártica (Gardiner, 1975); Chile: isla de Pascua.

Nota: probablemente la especie registrada en isla de Pascua corresponde a una especie diferente.

\section{Exogone yagan}

Soto, San Martín \& Peñaloza, en prensa

Exogone yagan Soto et al. en prensa.

Localidad tipo: región de Magallanes, canal

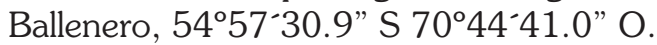

Distribución: Chile: hasta ahora conocida sólo en la localidad tipo, región de Magallanes.

Género Parapionosyllis Fauvel, 1923

Parapionosyllis Fauvel, 1923, pp. 289-290

26. Parapionosyllis brevicirra Day, 1954

Parapionosyllis brevicirra Day, 1954: 16, fig. $2 \mathrm{j}$-o.

Localidad tipo: isla Nightingale, Tristan da Cunha, 20-40 m.

Nota: Orensanz (1976) ubica a P. brevicirra sensu Hartmann-Schröder en la sinonimia de Parapionosyllis retrodens, luego de cambiar a esta última especie del género Sphaerosyllis.

Referencias para Chile: Hartmann-Schröder, 1962: 98-99, figs. 81-83; 1965: 292. Soto et al., en prensa.

Localidades de registro en Chile: Ahínco- 

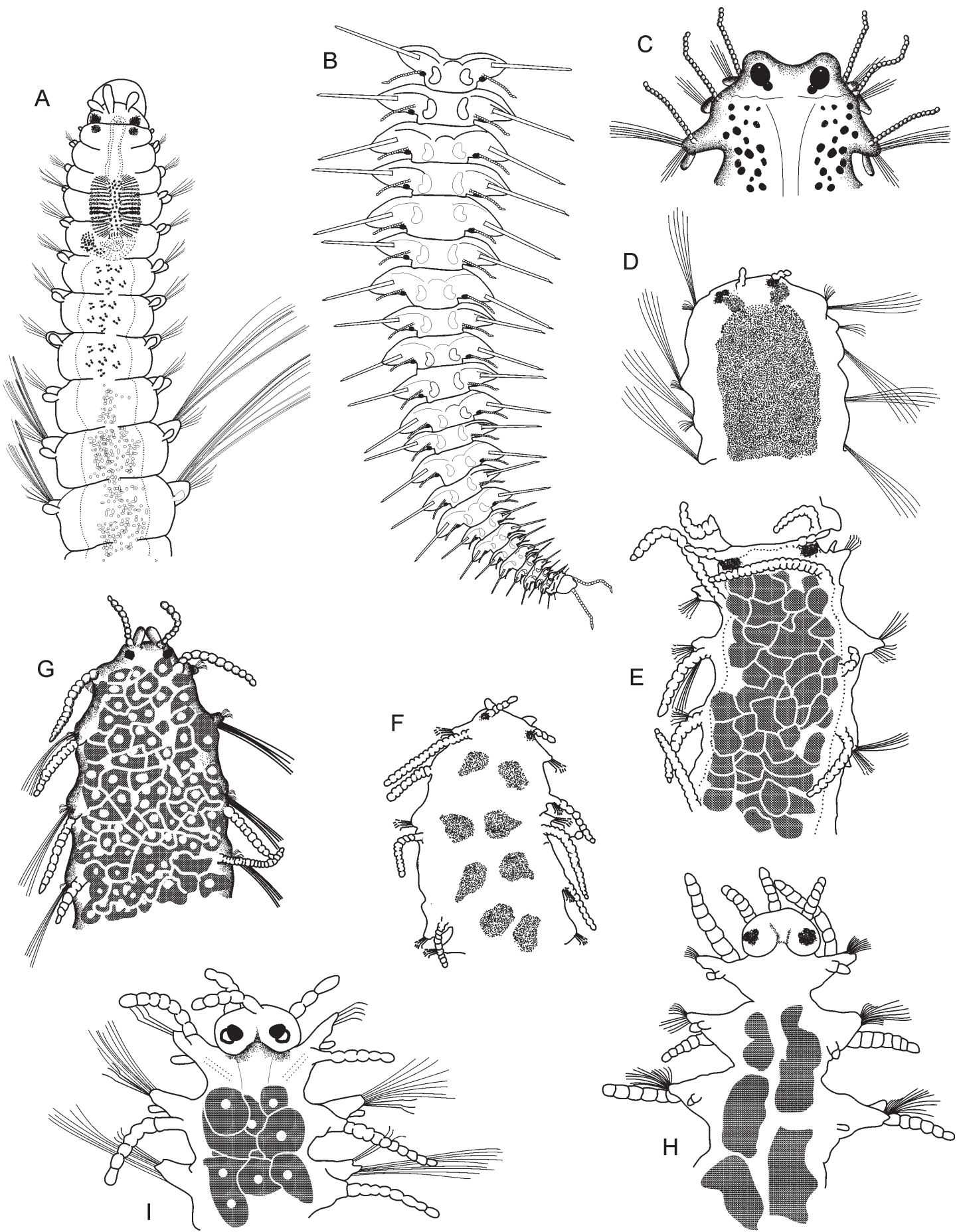

Fig. 5. A, macho epigámico de Exogone naidina. Parte anterior de estolones.

B, acéfalo (macho aún sujeto al parental), Haplosyllis spongicola; C, ácero (macho), Trypanosyllis zebra;

$\mathrm{D}$, dícero (macho), Syllis prolifera; E, dícero (hembra, aún sujeto al parental), S. prolifera; F, tetrácero (macho),

Syllis pulvinata; G, tetrácero (hembra), S. pulvinata; H, pentácero (macho), Syllis hyalina; I, pentácero (hembra),

S. hyalina. En todos los casos, vista dorsal, excepto H, vista ventral. (Modificado de San Martín, 2003). 
Pargua ( $\left.41^{\circ} 48^{\prime} \mathrm{S}\right)$, ribera $\mathrm{N}$ del canal de Chacao (Hartmann-Schröder, 1965). Punta Arenas (53¹0' S), estrecho de Magallanes (Hartmann-Schröder, 1962); región de Magallanes (Soto et al. en prensa).
Distribución: España (cabo de Creus e islas Baleares); Tristan da Cunha; Chile: ribera norte del canal de Chacao $\left(41^{\circ} 48^{\prime} \mathrm{S}\right)$ y estrecho de Magallanes (531's).

Género Parexogone Mesnil \& Caullery, 1918

Parexogone Mesnil \& Caullery, 1918, p. 126

Clave para las especies del Género Parexogone registradas en Chile

1a Todos los apéndices (antenas y cirros) de tamaño diminuto, papiliformes

P. minuscula (Hartman, 1953)

$1 \mathrm{~b} \mathrm{Al} \mathrm{menos,} \mathrm{algunas} \mathrm{antenas} \mathrm{alargadas}$

2a Las tres antenas insertas muy próximas entre si, en la parte basal del prosotomio

P. homosetosa Hartmann-Schröder, 1965

2b Las antenas laterales se insertan muy por delante de la antena central

3a La antena central es de tamaño similar a la longitud del prostomio; todas las sedas compuestas presentan artejos falcígeros cortos

P. parahebes Hartmann-Schröder, 1965

3b La antena central es de tamaño similar a la longitud del prostomio más los palpos; algunas sedas compuestas presentan artejos largos P. tasmanica Hartmann-Schröder, 1965

\section{Parexogone homosetosa}

(Hartmann-Schröder, 1965)

Exogone homosetosa Hartmann-Schröder, 1965, pp. 295-297, figs. 296-297. Exogone (Parexogone) homosetosa: San Martín, 2005, pp. 121-122, fig. 73.

Localidad tipo: Ahínco-Pargua $\left(41^{\circ} 48^{\prime}\right.$ S), ribera $\mathrm{N}$ del canal de Chacao.

Distribución: hasta ahora conocida sólo en Chile en la localidad tipo, Ahínco-Pargua, y en Australia.

28. Parexogone minuscula (Hartman, 1953)

Exogone minuscula Hartman, 1953, pp. 2627, fig. 5 a-f.

Localidad tipo: Moraine Fjord, isla South Georgia, 148 m.

Referencia para Chile: Exogone minuscula: Hartmann-Schröder, 1965, 126-127, 295.

Localidades de registro en Chile: Pelluco (4129' S), Ede la ciudad de Puerto Montt, intermareal; golfo de Ancud, SE de isla Tabón, 264 m (Expedición MarChile I St. X3: $42^{\circ} 00^{\prime}$ S, 7300,5' O, HartmannSchröder, 1965).

Distribución: Antártica y subantártica (sector occidental) (Orensanz, 1976); Chile: Puerto Montt (4129' S) y golfo de Ancud $42^{\circ} 00^{\prime}$ S. Recientemente, ha sido redescrita y citada para aguas profundas en Brasil por Barroso et al. 2017.

\section{Parexogone parahebes}

(Hartmann-Schröder, 1965) n. comb.

Exogone parahebes Hartmann-Schröder, 1965, pp. 127-129, figs. 93-95.

Localidad tipo: frente a isla Mocha, $26 \mathrm{~m}$.

Referencia para Chile: Hartmann-Schröder, 1965, p. 295.

Localidades de registro en Chile: NE de isla Mocha, frente a punta Nena, 26 m (Expedición MarChile I St. 75: 38 $15,9^{\prime}$ S, 73 ${ }^{\circ} 33^{\prime}$ O); Pelluco (4129' S), E de la ciudad de Puerto Montt, intermareal (Hartmann-Schröder, 1965).

Distribución: Hasta ahora conocida sólo en Chile, frente a isla Mocha (38 $15,9^{\prime}$ S) y Puerto Montt (4129'S).

\section{Parexogone tasmanica}

(Hartmann-Schröder, 1989)

Exogone obtusa tasmanica HartmannSchröder, 1989, p. 31, figs. 38-43. 


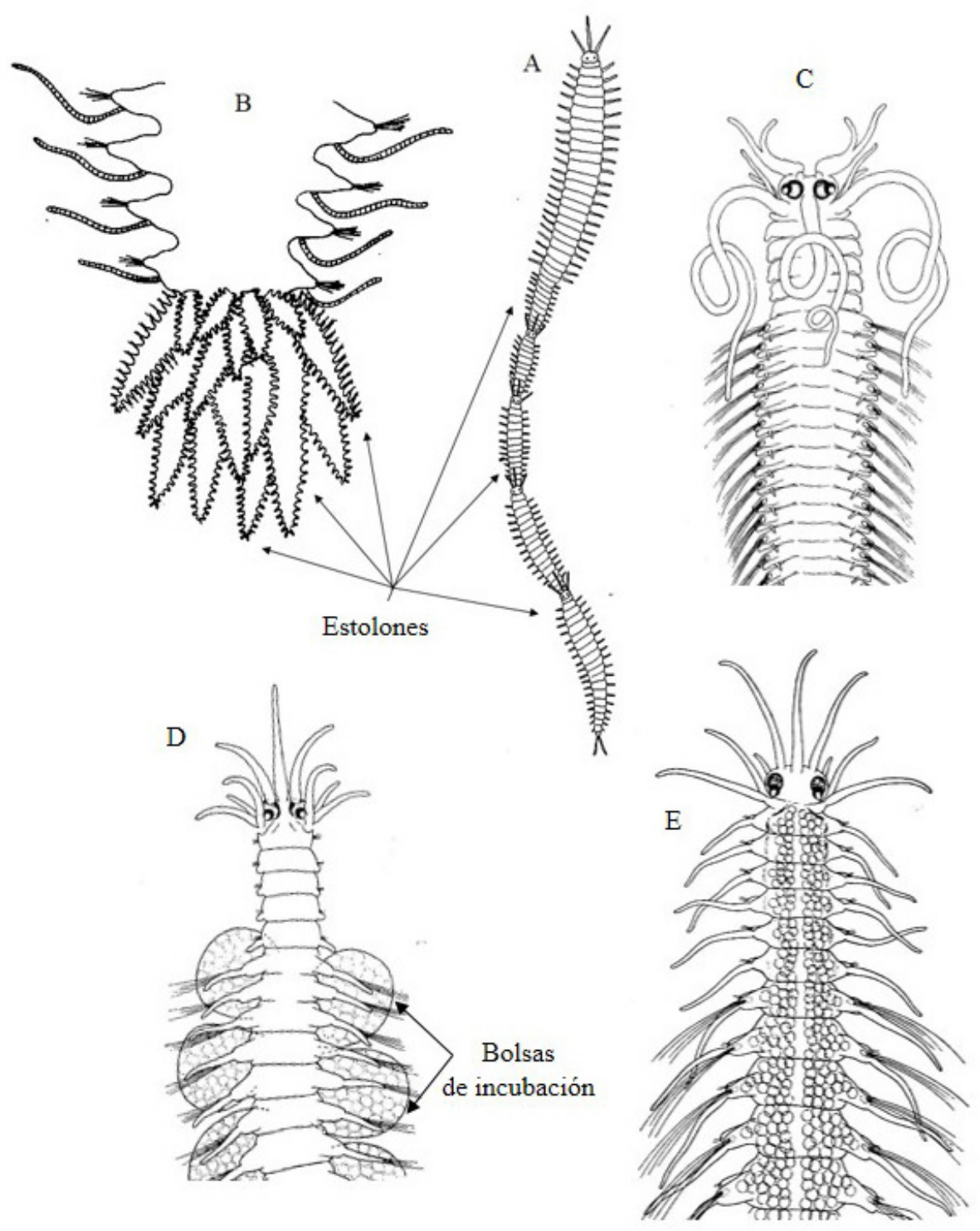

Fig. 6. A) Racimos de estolones, B, Cadena de estolones; C) Polybostrichus; D) Sacconereis, con incubación en un saco ventral. E) Sacconereis. (A-B: Modificado de Liñero-Arana \& DíazDíaz, 2011; C-E: Modificado de San Martín, 2003).

Exogone (Parexogone) tasmanica: San Martín, 2005, pp. 118-119, fig. 70.

Localidad tipo: isla de Tasmania.

Referencia para Chile: Exogone obtusa tasmanica: Hartmann-Schröder, 1991, p. 41.

Localidad de registro en Chile: bahía Quillaipe (4136' S), seno Reloncaví, en arena.

Distribución: isla de Tasmania (HartmannSchröder, 1991), Australia (New South Wales,
Queensland) (San Martín, 2005) y Chile: bahía Quillaipe, seno Reloncaví.

Género Prosphaerosyllis San Martín, 1984 Prosphaerosyllis San Martín, 1984, p. 384.

Tres especies registradas en Chile podrian pertenecer a este género: Sphaerosyllis brandhorsti Hartmann-Schröder, 1965; 
Sphaerosyllis sublaevis Ehlers, 1913 y Sphaerosyllis kerguelensis McIntosh, 1885, pero sus descripciones son tan incompletas que no se puede afirmar con exactitud la pertenencia de dichas especies a este género.

\section{Prosphaerosyllis (?) brandhorsti}

(Hartmann-Schröder, 1965) n. comb.

Sphaerosyllis brandhorsti HartmannSchröder, 1965, pp. 124-126, figs. 88-91.

Localidad tipo: isla Mocha ( $38^{\circ} 15,9^{\prime}$ S), 26 m.

Localidades de registro en Chile: NE de isla Mocha, frente a punta Nena, 26-160 m; punta Galera, 126-260 m; cabo Quedal, 136$220 \mathrm{~m}$; bahía de Ancud, puerto Inglés, $12 \mathrm{~m}$; golfo de Ancud, SE de isla Tabón, 264 m; frente a cabo Metalqui, O de la isla de Chiloé, 174 m (Expedición MarChile I St. 75: 38¹5,9' S, 733' O, St. 77: $38^{\circ} 16^{\prime} \mathrm{S}, 73^{\circ} 47,5^{\prime} \mathrm{O}$, St. 95: 3959' S, $73^{\circ} 54,5^{\prime}$ O, St. 96: 3959,9' S, $74^{\circ} 01,5^{\prime}$ O, St. 108 : $40^{\circ} 53,5^{\prime}$ S, $73^{\circ} 58,5^{\prime}$ O, St. 106 : $40^{\circ} 55,4^{\prime}$ S, $74^{\circ} 12,5^{\prime}$ O, St. X3: $42^{\circ} 00^{\prime} \mathrm{S}, 73^{\circ} 00,5^{\prime} \mathrm{O}$, St. $111: 42^{\circ} 16,5^{\prime} \mathrm{S}$, 74³2,5' O, Hartmann-Schröder, 1965).

Distribución: Hasta ahora conocida sólo en Chile, desde frente a isla Mocha (38 $15,9^{\prime}$ S) hasta frente a cabo Metalqui $\left(42^{\circ} 16,5^{\prime}\right.$ S), Chiloé.

\section{Prosphaerosyllis (?) kerguelensis} (McIntosh, 1885) n. comb.

Sphaerosyllis kerguelensis McIntosh, 1885, pp. 206-207, lám. 29, fig. 5, lám. 33, fig. 10, lám. 15A, fig. 22.
Localidad tipo: islas Kerguelen, frente a bahía Cumberland (4845’ S, 69¹4' E), 232 m.

Referencias para Chile: Sphaerosyllis retrodens Ehlers, 1897, pp. 46-48, lám. 2, figs. 53-57; 1901b: 96; Wesenberg-Lund, 1962, pp. 63-64, fig. 20.

Localidades de registro en Chile: Coquimbo, bahía Herradura de Guayacán, intermareal; bahía San Vicente, punta Liles, intermareal (Lund University Chile Expedition St. M124: 2957'55" S, 71'22'17" O, St. M121: 3643'36" S, 7308'10" O, Wesenberg-Lund, 1962). Punta Arenas (53 $\left.{ }^{\circ} 10^{\prime} \mathrm{S}\right)$, estrecho de Magallanes; canal Beagle (Ushuaia, 54²9' S), 3,6 m (Ehlers, 1897). Puerto Stewart (5454' S), isla Stewart, 36 m (Ehlers, 1901b).

Distribución: islas Kerguelen; islas Falkland (Malvinas) (Hartman, 1964); Chile: desde Coquimbo (2957'55”S) hasta isla Stewart (5454'S).

\section{Prosphaerosyllis (?) sublaevis}

(Ehlers, 1913) n. comb.

Sphaerosyllis sublaevis Ehlers, 1913, pp. 482-483, lám. 32, figs. 10-15.

Localidad tipo: Simonstown, False Bay, Sudáfrica.

Referencia para Chile: Sphaerosyllis sublaevis: Wesenberg-Lund, 1962, p. 65.

Localidades de registro en Chile: bahía de Ancud, SE de punta Ahui, $8 \mathrm{~m}$ (Lund University Chile Expedition St. M98: 4150'10" S, 7351'20" O, Wesenberg-Lund, 1962).

Distribución: Sudáfrica (Day, 1967); Australia (Hutchings \& Murray, 1984); Chile: bahía de Ancud (4150'10”S).

\section{Género Salvatoria McIntosh, 1885}

Salvatoria McIntosh, 1885, p. 188; San Martín, 2005, p. 49.

Clave para las especies del género Salvatoria registradas en Chile

1a Tamaño relativamente grande (más de $9 \mathrm{~mm}$ de longitud). Cirros dorsales relativamente cortos y gruesos. Sedas compuestas con espinas largas en el margen .................. S. nutrix (Monro, 1936) $1 \mathrm{~b}$ Tamaño menor (hasta unos $3 \mathrm{~mm}$ de longitud). Cirros dorsales relativamente largos y delgados. Sedas compuestas lisas o con espinas cortas en el margen ............................................... 2 2a Sedas unidentadas y lisas, excepto la más dorsal, que tiene un diente proximal muy pequeño y espinas cortas en la base

S. limbata (Claparède, 1868) $2 \mathrm{~b}$ Sedas compuestas bidentadas y con espinas cortas en el margen ... S. rhopalophora (Ehlers, 1897) 
34. Salvatoria limbata (Claparède, 1868)

Grubea limbata Claparède, 1868, p. 518, lám. 13, fig. 4.

Salvatoria limbata: San Martín, 2003, pp. 166-169, figs. 82, 83.

Localidad tipo: Nápoles.

Referencias para Chile: Brania limbata: Hartmann-Schröder, 1962, p. 103; 1965, pp. 292-293; Kohn \& Lloyd, 1973, pp. 695-696.

Localidades de registro a lo largo de la costa de Chile e isla de Pascua: Iquique (20 $12^{\circ}$ S); Taltal $\left(25^{\circ} 25^{\prime}\right.$ S) (Hartmann-Schröder, 1962). Taltal; El Quisco (3323' S), S de Algarrobo; desembocadura de la quebrada de Córdova (3326' S), N de El Tabo (Hartmann-
Schröder, 1965). Isla de Pascua, entre HangaRoa y Hanga-Piko, en poza de marea (Kohn \& Lloyd, 1973).

Distribución: océano Atlántico Norte y Sur; mar Mediterráneo; mar Negro; mar Rojo; costa de California; México occidental (Kohn \& Lloyd, 1973); Argentina (puerto Madryn, golfo Nuevo) (Hartmann-Schröder, 1962); Chile: desde Iquique $\left(20^{\circ} 12^{\prime}\right.$ S) hasta la quebrada de Córdova (3326' S) e isla de Pascua. Muy probablemente la cita de esta especie en isla de Pascua se refiere a otra especie diferente.

35. Salvatoria nutrix (Monro, 1936) n. comb.

Pionosyllis nutrix Monro, 1936, pp. 128
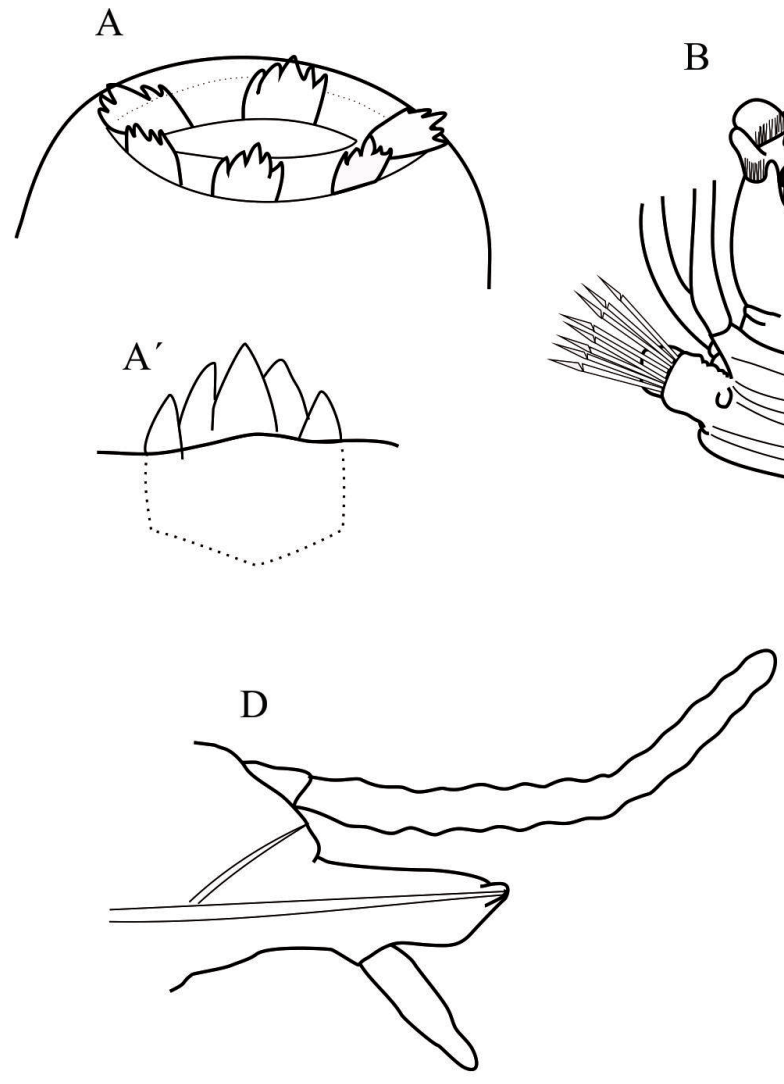

$\mathrm{B}$
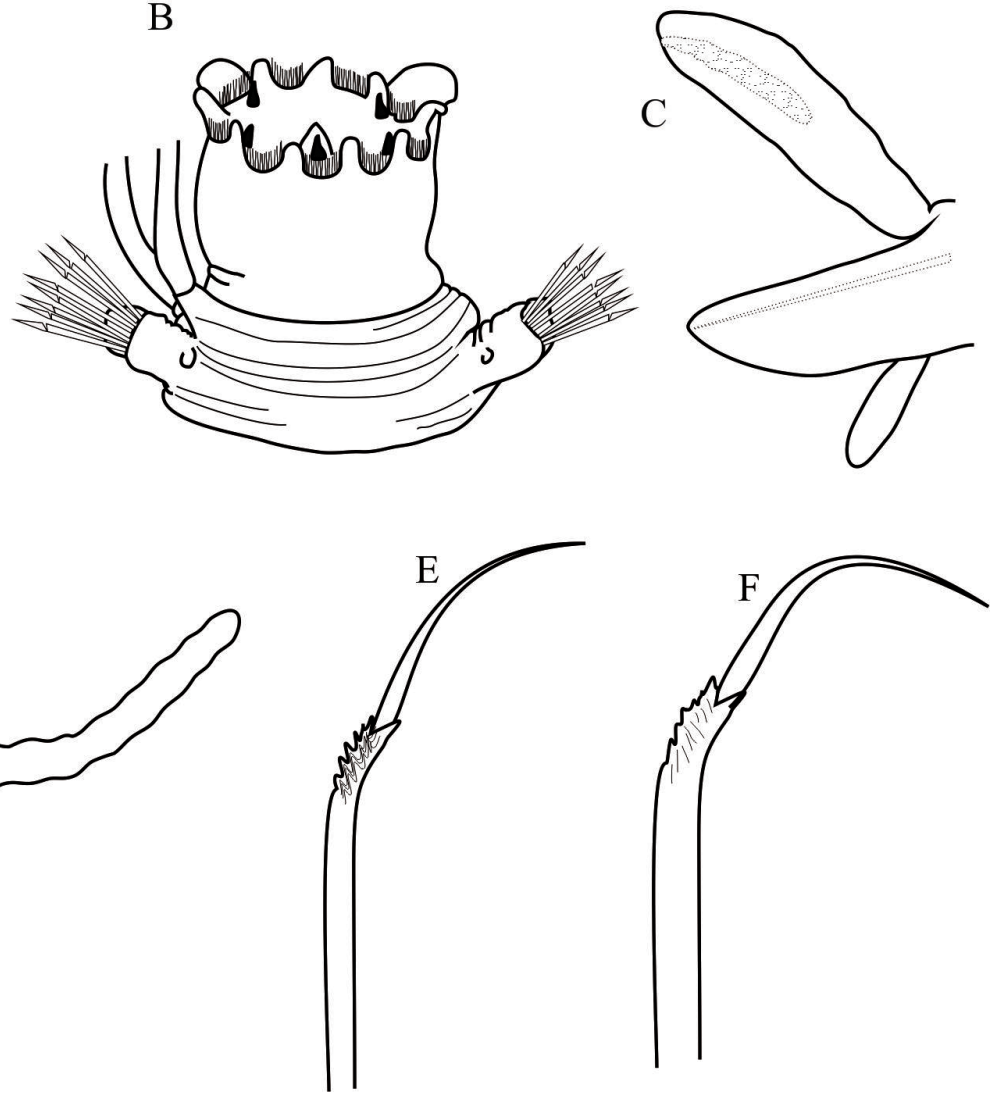

Fig. 7. Amblyosyllis A) extremo distal de la faringe, $\mathrm{A}^{-}$) detalle del diente pentacúspide; Brachysylls infuscata B) extremo distal de la faringe; Anoplosyllis sexoculata C) parápodo medio; Syllides articulosus D) parápodo medio; Myrianida spp. E) seda bayoneta estrecha;

Proceraea spp. F) seda bayoneta ancha. (Modificado de: A) Imajima \& Hartman, 1964;

B) Aguado \& San Martín, 2008; C) San Martín \& Hutchings, 2006; D) Ehlers, 1897). 
129, fig. 21.

Grubeosyllis nutrix: Jiménez et al. 1994, pp. 53-54, figs. 3, 4.

Salvatoria nutrix: Álvarez-Campos \& Verdes, 2017, p. 4.

Localidad tipo: Moltke Harbour, isla South Georgia.

Referencias para Chile: Pionosyllis nutrix: Wesenberg-Lund, 1962, p. 62. Grubeosyllis nutrix: Jiménez, San Martín \& López, 1994, pp. 53-54 (nueva combinación; revisión del material tipo depositado en el British Museum of Natural History of London, BMNH).

Localidades de registro en Chile: Cavancha, $S$ de Iquique, intermareal (Lund University Chile Expedition St. M135: 20¹4'07” S, 70¹0'05” O, Wesenberg-Lund, 1962). Playa Las Cruces (3330' S, 713' W), Chile central (Álvarez-Campos \& Verdes, 2017).

Distribución: mares antárticos y subantárticos; océano Antártico: península Antártica; océano Atlántico: South Georgia; océano Indico: Port Jeanne d'Arc (islas Kerguelen); océano Pacífico: islas Snares (Nueva Zelanda); Chile: Iquique (20¹4'07" S) y playa Las Cruces (3330’ S).

36. Salvatoria rhopalophora (Ehlers, 1897)

Grubea rhopalophora Ehlers, 1897, pp. 53-55, lám. 3, figs. 66-70. prensa).

Salvatoria rhopalophora: Soto et al. (en

Localidad tipo: canal Beagle (Ushuaia, 544'ㄱ), 1,8-3,6 m.

Referencias para Chile: Brania rhopalophora: Hartman, 1964, p. 79, lám. 25, fig. 1; 1967, pp. 54-55 (sólo se cita). Grubea rhopalophora: Wesenberg-Lund, 1962, p. 65. Salvatoria rhopalophora Soto et al. (en prensa).

Localidades de registro en Chile: seno Reloncaví, frente a Puerto Montt, NE de isla Tenglo, 13-16 m (Lund University Chile Expedition St. M4: 41'28'54" S, 7257'24" O, WesenbergLund, 1962); canal Beagle (Ushuaia, 5449' S), 1,8-3,6 m (Ehlers, 1897); región de Magallanes (Soto et al., en prensa).

Distribución: islas Cabo Verde; Namibia; Sudáfrica; sur de Australia; Nueva Zelanda; islas Falkland (Malvinas); islas subantárticas; Antártida
(Hartmann-Schröder \& Rosenfeldt, 1988); islas Kerguelen (Hartman, 1964); Chile: desde el seno Reloncaví (4128'54" S) hasta el canal Beagle (544' S).

\section{Género Sphaerosyllis Claparède, 1863} Sphaerosyllis Claparède, 1863, p. 45.

Cuatro especies que podrían pertenecer a este género han sido citadas para la costa de Chile: Sphaerosyllis capensis chilensis HartmannSchröder, 1962, S. dubiosa Hartmann-Schröder, 1962, S. hirsuta Ehlers, 1897, y S. hystrix Claparède, 1863. Las descripciones de las dos primeras son incompletas, y la última es una especie de aguas europeas que muy posiblemente no habite en las costas chilenas, pudiéndose tratar de alguna otra especie.

\section{Sphaerosyllis capensis chilensis}

Hartmann-Schröder, 1962

Sphaerosyllis capensis chilensis HartmannSchröder, 1962, pp. 103-104, figs. 93-96. (414ㅇ's).

Localidad tipo: puerto de Calbuco

Otras localidades de registro en Chile: Arica (18 28' S), 1 m; Pelluco (4129' S), E de la ciudad de Puerto Montt; Ahínco-Pargua (4148' S), ribera $\mathrm{N}$ del canal de Chacao (Hartmann-Schröder, 1965). Puerto de Calbuco (41 $46^{\prime}$ S) (HartmannSchröder, 1962).

Distribución: hasta ahora conocida sólo en Chile, desde Arica (18 $28^{\prime}$ S) hasta el canal de Chacao (41ㄴㅇ' S).

\section{Sphaerosyllis dubiosa}

Hartmann-Schröder, 1962

Sphaerosyllis dubiosa Hartmann-Schröder, 1962, pp. 104-106, figs. 97-99.

Localidad tipo: $4 \mathrm{~km}$ al norte de Taltal.

Distribución: hasta ahora conocida sólo en Chile en la localidad tipo, Taltal $\left(25^{\circ} 25^{\prime} \mathrm{S}\right)$, norte de Chile.

39. Sphaerosyllis hirsuta Ehlers, 1897

Sphaerosyllis hirsuta Ehlers, 1897, pp. 48- 
50, lám. 3, figs. 58-60.

Localidad tipo: Punta Arenas (5310'S), estrecho de Magallanes.

Otras referencias para Chile: Ehlers, 1901b, p. 97; Augener, 1922, pp. 189-190; Hartman, 1953 , p. 25 ; 1964 , pp. $88-89$, lám. 28, figs. 1-2; Wesenberg-Lund, 1962, p. 63; Soto et al. (en prensa).

Localidades de registro a lo largo de la costa de Chile y el archipiélago Juan Fernández: seno Reloncaví, E de punta Ilque, 390 m; estrecho de Magallanes, S de Punta Arenas, estuario Río Los Ciervos, intermareal (Lund University Chile Expedition St. M146: 41 ${ }^{\circ} 37^{\prime} 15^{\prime \prime}$ S, 7302'30" O, St. M115: 5311' S, 7055' O, WesenbergLund, 1962). Punta Arenas (5310' S), estrecho de Magallanes; canal Beagle (Ushuaia, 5449' S), 3,6 m (Ehlers, 1897). Región de Magallanes (Soto et al., en prensa). Canal Beagle, Ushuaia y entre Ushuaia y Lapataia (Swedish Antarctic Expedition St. 64: 5452' S, 68 $25^{\circ}$ O, St. 67: 5449' S, 68¹6' O, Hartman, 1953). Archipiélago Juan Fernández, isla Robinson
Crusoe, 30-45 m (Augener, 1922).

Distribución: Japón; Antártida; región subantártica (Orensanz, 1976); islas Kerguelen (Wesenberg-Lund, 1962); Chile: desde el seno Reloncaví (4137'15"S) hasta el canal Beagle (5452'S) y en el archipiélago Juan Fernández, isla Robinson Crusoe.

\section{Sphaerosyllis hystrix Claparède, 1863}

Sphaerosyllis hystrix Claparède, 1863, p. 45, lám. 13, figs. 36-37.

Localidad tipo: costa de Normandía.

Referencia para Chile: isla de Pascua (Kohn \& Lloyd, 1973, p. 696).

Localidad de registro en isla de Pascua: entre bahía Hanga-Roa y Hanga-Piko, en poza de marea (Kohn \& Lloyd, 1973).

Distribución: Pacífico norte; Atlántico norte; Mar del Norte; mar Mediterráneo; islas Galápagos (Westheide, 1974); América del Norte desde Canadá a México (Pettibone, 1963); Chile: isla de Pascua.

Subfamilia Syllinae Grube, 1850

Clave para los géneros de la subfamilia Syllinae registrados en Chile

1a Todas las sedas son simples, gruesas y poco numerosas

Haplosyllis

$1 \mathrm{~b}$ Con sedas compuestas (en algunos casos puede haber sedas pseudosimples por fusión del mango y

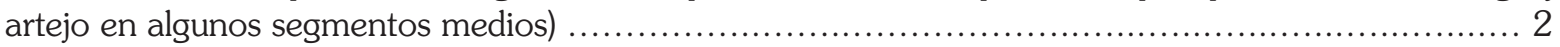

2a Cuerpo aplanado dorso-ventralmente; faringe armada de un trépano .............................. 3

2b Cuerpo cilíndrico; faringe armada de un único diente medio dorsal .................................. 4

3a. Reproducción mediante un estolón único ....................................... Trypanosyllis

3b. Reproducción mediante una cadena o un racimo de estolones ........................ Trypanedenta 4a Al menos en los parápodos medios y posteriores con sedas en forma de garra curvada (úngulas); sin sedas simples capilares

Branchiosyllis

$4 \mathrm{~b}$ Sin úngulas; con sedas capilares dorsales y ventrales en los parápodos posteriores

Género Branchiosyllis Ehlers, 1887

Branchiosyllis Ehlers, 1887, p. 148.

\section{Branchiosyllis verruculosa}

(Augener, 1913)

Syllis (Typosyllis) verruculosa Augener, 1913, p. 203, textfig. 24 a-c, lám. 3, fig. 39.
Branchiosyllis verruculosa: Licher, 1999, p. 274 .

Localidad tipo: Australia sudoccidental.

Referencia para isla de Pascua: Syllis (Typosyllis) verruculosa: Kohn \& Lloyd, 1973, p. 695.

Localidad de registro en isla de Pascua: entre bahía Hanga-Roa y Hanga-Piko, en poza de 

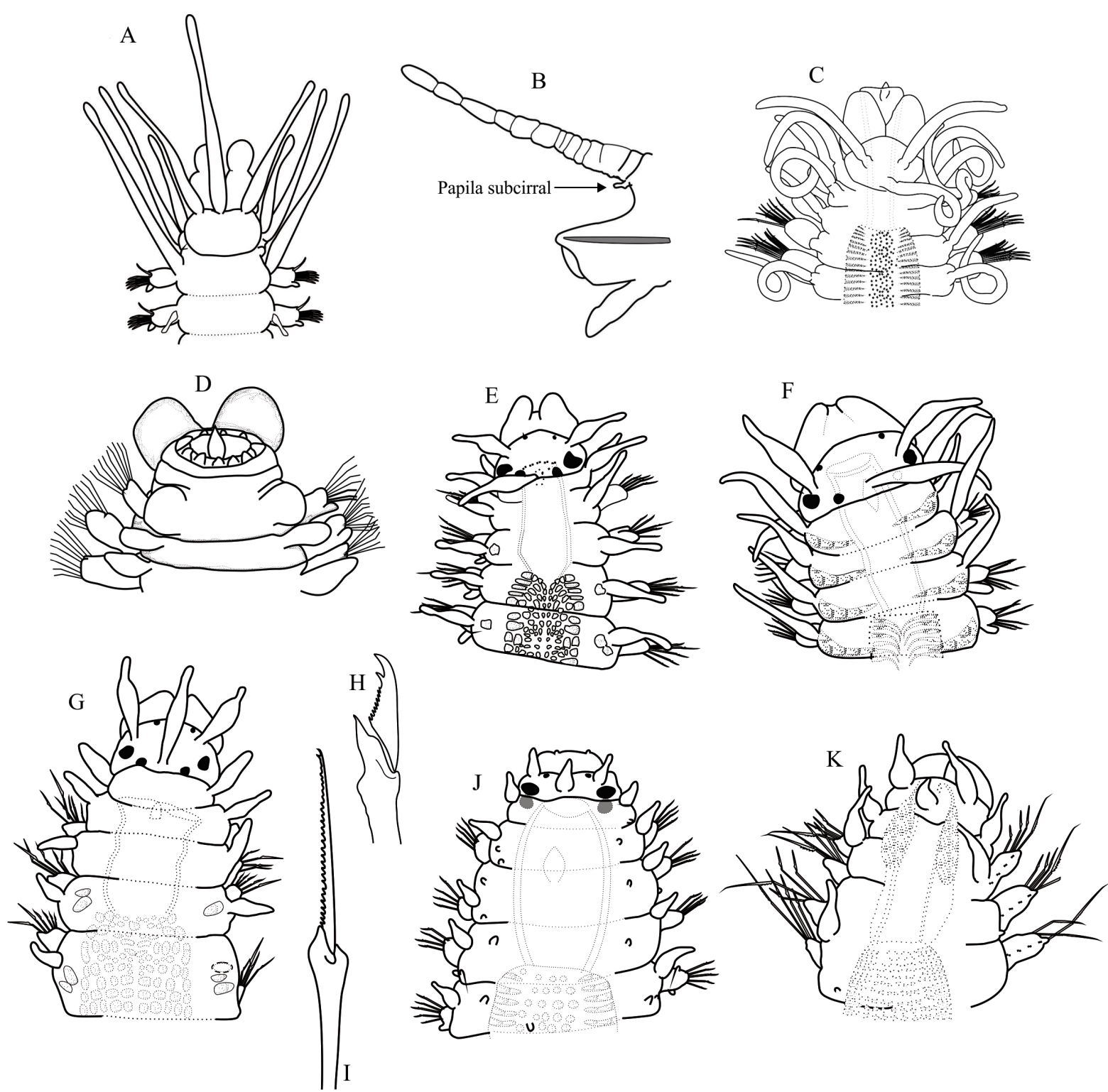

Fig. 8. Subfamilia Eusyllinae e Incertae Sedis: A) Neopetitia extremo anterior en vista dorsal; B) Paraehlersia parapodio motrando la papila subcirral; C) Perkinsyllis, extremo anterior en vista dorsal D) Pionosyllis compacta, extremo anterior en vista ventral. (Figuras A-C (consideradas Incertae Sedis) modificadas de San Martín, 2003; Figura D, modificada de San Martín et al.

2009). Subfamilia Exogoninae: A) Brania arminii, extremo anterior en vista dorsal; B) Salvatoria vieitezi, en vista dorsal; C) Parapionosylls brevicirra; D) Paraexogone sp. seda compuesta;

E) Exogone sp., seda compuesta ; F) Prosphaerosyllis campoy, extremo anterior en vista dorsal;

G) Erinaceusyllis serrasetosa, extremo anterior en vista dorsal (Figuras modificadas de: A, C-E, G) San Martín, 2003; B) San Martín, 1984; F) San Martín, 2005). 
marea (Kohn \& Lloyd, 1973).

Distribución: Zanzíbar (Monro, 1939); Australia (Augener, 1913; San Martín et al. 2008); Indonesia (Aguado et al. 2008); Chile: isla de Pascua.

Género Haplosyllis Langerhans, 1879 Syllis (Haplosyllis) Langerhans, 1879, p. 527.

La única especie de este género registrada en Chile es Haplosyllis spongicola (Grube, 1855), pero posiblemente se trate de otra especie, ya que la verdadera $H$. spongicola parece estar restringida a las costas europeas y del Mediterráneo, a pesar de haber sido citada en todo el mundo (Lattig et al. 2007).

\section{Haplosyllis spongicola (Grube, 1855)}

Syllis spongicola Grube, 1855, pp. 104-
105, lám. 4, fig. 4. p. 398.

Haplosyllis spongicola: Amoureux, 1977,

Localidad tipo: Trieste, mar Adriático.

Referencia para Chile (isla de Pascua): Syllis (Haplosyllis) spongicola: Kohn \& Lloyd, 1973, p. 694.

Localidad de registro en isla de Pascua: entre bahía Hanga-Roa y Hanga-Piko, en poza de marea (Kohn \& Lloyd, 1973).

Distribución: citada como cosmopolita en mares templados y cálidos (Kohn \& Lloyd, 1973; Capa, San Martín \& López, 2001), pero tras los trabajos de Martin et al. (2003), Lattig y Martin (2009) y Lattig et al. (2007), se ha comprobado que tal especie está realmente restringida al Atlántico nor-oriental y Mediterráneo, por lo que la cita de Chile en isla de Pascua, podría referirse en realidad a otra especie.

Género Syllis Lamarck, 1818 (p. 317)

Clave para las especies del género Syllis registradas en Chile

1a Con sedas pseudosimples gruesas (que resultan de la fusión del mango y el artejo) en algunos parápodos; el resto, con sedas compuestas no modificadas .......................................................... 2

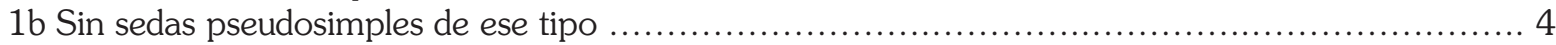
2a La fusión del mango con el artejo es distal, formando sedas similares a las de Haplosyllis, pero con la línea de fusión visible en algunas sedas

S. sclerolaema Ehlers, 1900 $2 \mathrm{~b}$ La fusión del artejo con el mango es lateral, formando sedas pseudosimples con forma de "Y" ...... 3 3a En los parápodos de la parte media del cuerpo hay una seda pseudosimple y una compuesta sin fusionar el mango y el artejo....

S. palifica Ehlers, 1901 3b Con varias (unas 5) sedas pseudosimples y compuestas, con distintos grados de fusión entre mangos y artejos S. magellanica Augener, 1918 4a Presencia de sedas de artejos largos y delgados (pseudoespinígeras) . .............................. 5

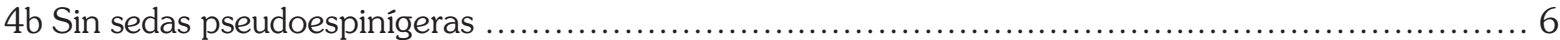
5 a Con ojos S. cornuta Rathke, 1843 $5 \mathrm{~b}$ Sin ojos S. anops Ehlers, 1897

6 bos cirros dorsales de la mitad del cuerpo son cortos, fusiformes ................................ 7

$6 \mathrm{~b}$ Los cirros dorsales son alargados, no fusiformes

7a Con gruesas sedas simples en posición dorsal por la pérdida de artejo y engrosamiento del mango S. albae Álvarez-Campos \& Verdes, 2017

$7 \mathrm{~b}$ Sin tales sedas .. 8

8a Los cirros dorsales son marcadamente fusiformes; las sedas de la mitad del cuerpo son unidentadas o casi unidentadas, con un diente proximal muy pequeño. S. valida Grube, 1857 $8 \mathrm{~b}$ Los cirros dorsales no son tan marcadamente fusiformes; con sedas compuestas bidentadas ....

S. hyalina juanensis Augener, 1922 
10a El diente proximal de los artejos de las sedas compuestas es fino, alargado, con la forma de una larga espina S. filidentata (Hartmann-Schröder, 1962)

$10 \mathrm{~b}$ El diente proximal es triangular 11

11a Las acículas son distalmente redondeadas, sin sobresalir del lóbulo parapodial

S. prolifera Krohn, 1852

$11 \mathrm{~b}$ Las acículas posteriores son rectas, y terminadas en punta, sobresaliendo del lóbulo parapodial ...12 12a Los cirros dorsales bastante largos con numerosas glándulas espiralizadas dentro de los artejos; acículas sobresaliendo poco de los lóbulos parapodiales ...... S. luteoides (Hartmann-Schröder, 1962) $12 \mathrm{~b}$ Sin tales glándulas en los cirros dorsales; acículas posteriores sobresaliendo claramente de los lóbulos parapodiales; en vivo o recientemente fijados, presentan un marcado patrón de coloración en forma de $\infty$ en los segmentos anteriores

S. variegata Grube, 1860

13a En los parápodos medios con una gruesa seda pseudosimple, por pérdida del artejo .............. 14

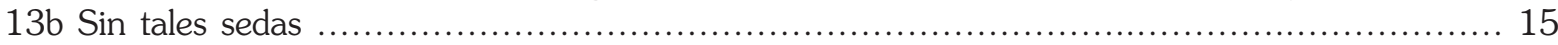

14a Cuerpo muy robusto, fuertemente pigmentado de oscuro, casi negro

14b Cuerpo largo y delgado, de color verde y amarillo

S. magdalena Wesenberg-Lund, 1962

S. tripantu Álvarez-Campos \& Verdes, 2017

$15 \mathrm{a}$ Sin ojos; artejos de las sedas compuestas con pocas espinas en el margen y con la punta dirigida hacia arriba (muy poco ganchuda)

S. anoculata (Hartmann-Schröder, 1962)

15b Con ojos; artejos más ganchudos y con más espinas en el margen .............................. 16

16a Acículas rectas y puntiagudas. Sedas compuestas bidentadas, con ambos dientes de tamaño similar

S. tamarae Álvarez-Campos \& Verdes, 2017

$16 \mathrm{~b}$ Acículas distalmente redondeadas, de punta roma

17a Diente faríngeo claramente alejado de la embocadura; artejos claramente unidentados, las espinas del son margen largas y gruesas

S. pectinans Haswell, 1920

$17 \mathrm{~b}$ Diente faríngeo solamente un poco alejado de la embocadura; los artejos de algunas sedas compuestas con un pequeño diente proximal y con espinas en el margen que no son tan marcadamente largas y gruesas

S. prolixa Ehlers, 1901

\section{Syllis albae}

Álvarez-Campos \& Verdes, 2017

Syllis albae: Álvarez-Campos \& Verdes, 2017, pp. 5-6, figs. 1-3, 9-13.

Localidad tipo: playa Las Cruces (3330'

S, 71³9' O), Chile central (Álvarez-Campos \& Verdes, 2017).

Distribución: hasta ahora conocida sólo en la localidad tipo, en Chile central.

\section{Syllis anoculata}

(Hartmann-Schröder, 1962) n. comb.

Typosyllis anoculata Hartmann-Schröder, 1962, p. 93, figs. 69-71.

Localidad tipo: $24 \mathrm{~km}$ al sur de Tocopilla $\left(22^{\circ} 04^{\prime} \mathrm{S}\right)$, norte de Chile.

Otra referencia para Chile: Typosyllis anoculata: Hartmann-Schröder, 1965, p. 288. Localidades de registro en Chile: Paposo (2503' S), N de Taltal, $0.5 \mathrm{~m}$; Taltal (25⒉ $5^{\prime} \mathrm{S}$ ); El Quisco (3323' S), S de Algarrobo (HartmannSchröder, 1965).

Distribución: hasta ahora conocida sólo en Chile, desde el sur de Tocopilla (22 $\left.{ }^{\circ} 04^{\prime} \mathrm{S}\right)$ hasta El Quisco (33²3' S), S de Algarrobo.

\section{Syllis anops Ehlers, 1897}

Syllis (Ehlersia) anops Ehlers, 1897, p. 40, lám. II, figs. 40-45.

Localidad tipo: Punta Arenas (5310'S), estrecho de Magallanes.

Otras referencias para Chile: Ehlers, 1901b: 88 (sólo se cita). Langerhansia anops: Hartman, 1964: 82-83, lám. 25, figs. 9-11. Syllis (Ehlersia) anops: Wesenberg-Lund, 1962, p. 58. 
Localidades de registro en Chile: seno Reloncaví, rada de Puerto Montt, $30 \mathrm{~m}$; golfo de Ancud, isla Quenu, intermareal (Lund University Chile Expedition St. M48: 41'28'50" S, 7256'50" O, St. M22: 4140'15” S, 73¹0'15" O, Wesenberg-Lund, 1962). Punta Arenas (53¹0' S), estrecho de Magallanes (Ehlers, 1897).

Distribución: Sudáfrica; islas Chatham (Day, 1967); Chile: Puerto Montt, seno Reloncaví; golfo de Ancud; Punta Arenas, estrecho de Magallanes.

46. Syllis cornuta Rathke, 1843

Syllis cornuta Rathke, 1843, p. 164-165, lám. 7, fig. 12.

Localidad tipo: Kristiansund, Noruega.

Referencias para Chile e isla de Pascua: Langerhansia cornuta: Hartmann-Schröder, 1965: 291. Syllis (Langerhansia) cornuta: Kohn \& Lloyd, 1973: 695.

Localidades de registro a lo largo de la costa de Chile e isla de Pascua: Arica (18 28'S), $1 \mathrm{~m}$ (Hartmann-Schröder, 1965). Isla de Pascua, entre bahía Hanga-Roa y Hanga-Piko, en poza de marea (Kohn \& Lloyd, 1973).

Distribución: Especie del norte de Europa, citada por todo el mundo, aunque probablemente se trate de otras especies, al igual que sucede con las citas de Chile (Arica (18 ${ }^{\circ} 8^{\prime}$ 'S) e isla de Pascua.

\section{Syllis filidentata}

(Hartmann-Schröder, 1962) n. comb.

Typosyllis filidentata Hartmann-Schröder, 1962, pp. 84-86, figs. 52-54.

Localidad tipo: San Julián, Argentina.

Referencia para Chile: Hartmann-Schröder, 1962: 84-86.

Localidad de registro en Chile: Iquique (20¹2'S) (Hartmann-Schröder, 1962).

Distribución: San Julián, Argentina, e Iquique, Chile.

48. Syllis hyalina juanensis Augener, 1922

Syllis (Typosyllis) hyalina juanensis Augener, 1922, p. 187-188, textfig. 6.

Localidad tipo: isla Robinson Crusoe (= Más a Tierra), archipiélago Juan Fernández, 30-45 m.
Distribución: hasta ahora conocida sólo en Chile en la localidad tipo, isla Robinson Crusoe, archipiélago Juan Fernández.

\section{Syllis luteoides}

(Hartmann-Schröder, 1962) n. comb.

Typosyllis luteoides Hartmann-Schröder, 1962, pp. 90-91, figs. 66-68. Chile.

Localidad tipo: Taltal $\left(25^{\circ} 25^{\prime} \mathrm{S}\right)$, norte de

Otra referencia para Chile: HartmannSchröder, 1965, p. 111, 288, figs. 68-70.

Localidades de registro en Chile: Arica (18 $28^{\prime}$ 'S), $1 \mathrm{~m}$; Pelluco (4129'S), E de la ciudad de Puerto Montt; Ahínco-Pargua (41 $48^{\prime}$ 'S), ribera $\mathrm{N}$ del canal de Chacao, $12 \mathrm{~m}$; golfo Corcovado, al E de isla Puduhuapi, 190 m (Expedición MarChile I St. X1: 4257'S, 7257'O, Hartmann-Schröder, 1965). Playa Las Cruces (33³0’ S, 71³9’ O), Chile central (Álvarez-Campos \& Verdes, 2017).

Distribución: hasta ahora conocida sólo en Chile, desde Arica (18 $\left.28^{\prime} \mathrm{S}\right)$ hasta el golfo Corcovado (4257'S).

\section{Syllis magdalena}

Wesenberg-Lund, 1962

Syllis magdalena Wesenberg-Lund, 1962, pp. 55-58, figs. 16-18.

Localidad tipo: islote Cayo Blanco, canal Moraleda, archipiélago de los Chonos, intermareal (4448'20" S).

Otras referencias para Chile: Typosyllis magdalena: Hartmann-Schröder, 1962, p. 82; 1965, p. 287.

Localidades de registro en Chile: Iquique, $\mathrm{S}$ de la ciudad, intermareal; península de Coquimbo, $\mathrm{S}$ de Roca Pelícanos, intermareal; Montemar, N de Valparaíso, "Estación de Biología Marina", intermareal; bahía San Vicente, Ramuncho, SE de punta Gualpén, intermareal; punta Liles, O de San Vicente, intermareal; golfo de Arauco, bahía de Lota, intermareal; canal Moraleda, islote Cayo Blanco, intermareal (Lund University Chile Expedition St. M131: 20¹3'10" S, 70¹0'19” O, St. M127:

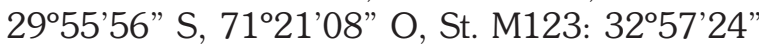
S, 71³3'25" O, St. M120: 3644'54" S, 73¹1'02" O, St. M121: 3643'36” S, 7308'10” O, St. M122: 
3706'17” S, 7309'15” O, St. M71: 4448'20” S, $73^{\circ} 35^{\prime}$ O, Wesenberg-Lund, 1962). Desembocadura

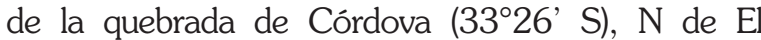
Tabo (Hartmann-Schröder, 1965). Playa Las Cruces

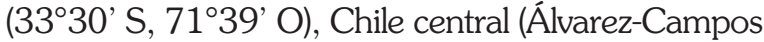
\& Verdes, 2017). Coronel ( $37^{\circ} 01^{\prime}$ S), golfo de Arauco (Hartmann-Schröder, 1962).

Distribución: Perú (Hartmann-Schröder, 1965) y Chile, desde Iquique (20¹3'10” S) hasta el canal Moraleda (4448'20" S).

\section{Syllis magellanica Augener, 1918}

Syllis gracilis magellanica Augener, 1918, pp. 265-269, figs. 24 a-d.

Localidad tipo: canal Beagle (Ushuaia, 54²49' S) y Punta Arenas (5310' S), estrecho de Magallanes.

Otras referencias para Chile: Syllis (Synsyllis) magellanica: Orensanz, 1976: 29 (nueva combinación). Syllis gracilis magellanica: Hartman, 1964, p. 92, lám. 27, figs. 10-13. Syllis hyalina Ehlers, 1897, pp. 36-37; 1901b, p. 86.

Localidades de registro en Chile: canal Beagle (Ushuaia, 544' S) y Punta Arenas, estrecho de Magallanes (Augener, 1918). Punta Arenas (5310' S), estrecho de Magallanes; canal Beagle (Ushuaia, 544ㅇ'S) (Ehlers, 1897).

Distribución: hasta ahora conocida sólo en Chile, desde el estrecho de Magallanes (5310' S) hasta el canal Beagle (5449' S).

\section{Syllis palifica Ehlers, 1901}

Syllis palifica Ehlers, 1901a, pp. 257-258.

Localidad tipo: bajo Tabón, Calbuco, golfo de Ancud (4146' S; 7306' O) (Ehlers, 1901a).

Distribución: hasta ahora conocida sólo en Chile, en la localidad tipo.

\section{Syllis pectinans Haswell, 1920}

Syllis (Typosyllis) pectinans Haswell, 1920: 93-94, lám. 10, figs. 3-6.

Localidad tipo: Port Jackson, Australia.

Referencias para Chile: Typosyllis pectinans: Hartmann-Schröder, 1962, pp. 82-83, figs. 4751; 1965, pp. 287-288. Syllis pectinans: ÁlvarezCampos \& Verdes, 2017, p. 4.

Localidades de registro en Chile: Taltal (2525'
S); El Quisco (3323' S), S de Algarrobo; Mehuín (39²6' S). Playa Las Cruces (3330' S, 71³9' O), Chile central (Álvarez-Campos \& Verdes, 2017). Coronel (37 $01^{\prime}$ S), golfo de Arauco (HartmannSchröder, 1962). Valdivia (Hartmann-Schröder, 1965).

Distribución: Australia; Japón; España (Galicia y Murcia) (San Martín, González \& López-Jamar, 1985); Chile: desde Taltal (2525' S) hasta Valdivia (3926' S).

\section{Syllis prolifera Krohn, 1852}

Syllis prolifera Krohn, 1852, p. 66, lám. 3, fig. 1 .

Localidad tipo: mar Mediterráneo.

Referencia para Chile (isla de Pascua): Syllis (Typosyllis) prolifera: Kohn \& Lloyd, 1973, p. 695.

Localidad de registro a lo largo de la costa de Chile e isla de Pascua: playa Las Cruces (3330' S, 7139' O), Chile central (Álvarez-Campos \& Verdes, 2017). Isla de Pascua, entre bahía Hanga-Roa y Hanga-Piko, en poza de marea (Kohn \& Lloyd, 1973).

Distribución: cosmopolita en mares templados y cálidos (Capa et al. 2001); Brasil (Nogueira \& San Martín, 2002); Chile: playa Las Cruces, Chile central $e$ isla de Pascua.

\section{Syllis prolixa Ehlers, 1901}

Syllis prolixa Ehlers, 1901b, pp. 92-95, lám. 9, figs. 1-7.

Localidad tipo: Chile (Valparaíso, Taltal e Iquique).

Otras referencias para Chile: Typosyllis prolixa: Hartmann-Schröder, 1962, pp. 81-82; 1965, p. 287; Hartman, 1964, pp. 95-96, lám. 29, figs. 6-7. Syllis (Typosyllis) prolixa: WesenbergLund, 1962, p. 51. Syllis longifilis Ehlers, 1901a, p. 258; 1901b, p. 95-96, lám. 10, fig. 3. Syllis prolixa: Álvarez-Campos \& Verdes, 2017, p. 4.

Localidades de registro en Chile: Iquique

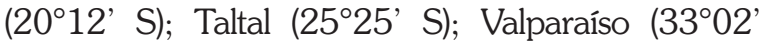
S) (Ehlers, 1901b). Cavancha (20¹4’ S) (Ehlers, 1901a). Iquique, parte $S$ de la ciudad, intermareal; Cavancha, S de Iquique, intermareal; Tocopilla, S de la ciudad, intermareal y hasta $13 \mathrm{~m}$; Antofagasta, bahía Mejillones del Sur, 0-0.5 m; rada de Antofagasta, 
intermareal; península de Coquimbo, bahía de Coquimbo, 0-0.5 m; Montemar, $\mathrm{N}$ de Valparaíso, "Estación de Biología Marina", intermareal; bahía San Vicente, punta Liles, intermareal; estero Reloncaví, bahía Ralún, banco Petrohué, intermareal; seno Reloncaví, isla Tenglo, intermareal; canal de Chacao, N de punta San Gallán, 80-100 m; bahía de Ancud, península Lacui, punta Corona, intermareal; bahía de Ancud, SE de punta Ahuí, $8 \mathrm{~m}$; estrecho de Magallanes, punta Santa María, S de Punta Arenas, intermareal (Lund University Chile Expedition St. M131: 20¹3'10" S, 70¹0'19" O, St. M135:

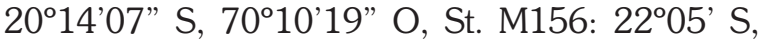
$70^{\circ} 13^{\prime}$ O, St. M158: $22^{\circ} 05^{\prime}$ S, $70^{\circ} 13^{\prime}$ O, St. M129: 2306'30" S, 70²8' O, St. M159: 2339' S, 70²5' O, St. M127: 2955'56” S, 71²1'08” O, St. M128:

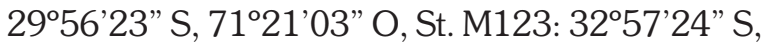
71'33'25" O, St. M121: 3643'36” S, 7308'10"

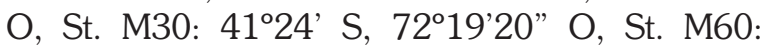

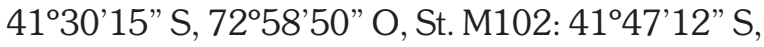
7332'50” O, St. M56: 4147' S, 7353'07” O, St. M98: 4150'10” S, 7351'20” O, St. M113: 5322' S, 7057' O, Wesenberg-Lund, 1962). Playa Las Cruces (3330' S, 71³9' O), Chile central (ÁlvarezCampos \& Verdes, 2017). Desembocadura del río Andalién (3640' S), bahía de Concepción; Coronel (3701' S), golfo de Arauco; Mehuín (39 26' S), Valdivia (Hartmann-Schröder, 1962). Mehuín (39²6' S), Valdivia (Hartmann-Schröder, 1965).

Distribución: islas Falkland (Malvinas); isla South Georgia (Hartman, 1964); Perú (HartmannSchröder, 1965); Tristan da Cunha (Orensanz, 1976); Chile: desde Iquique (20¹2' S) hasta el estrecho de Magallanes (5322' S).

\section{Syllis sclerolaema Ehlers, 1900}

Syllis sclerolaema Ehlers, 1900, p. 212. Localidad tipo: Última Esperanza, Magallanes, y bahía Harris y cabo Valentín, estrecho de Magallanes.

Imajima (1966) considera a Syllis sclerolaema sinónimo de S. spongiphila.

Otras referencias para Chile: Ehlers, 1901b, pp. 86-88, lám. 10, figs. 1-2; Hartman, 1953, pp. 20-21, figs. 2 a-f; 1964, p. 92, lám. 27, fig. 14; Hartmann-Schröder, 1965, pp. 110111, figs. 66-67). Syllis (Typosyllis) sclerolaema: Wesenberg-Lund, 1962, pp. 54-55, fig. 15.
Localidades de registro en Chile: Iquique, $\mathrm{S}$ de la ciudad, intermareal; península de Coquimbo, intermareal; seno Reloncaví, frente a Puerto Montt, entre la isla Tenglo y punta Pelluco, $225 \mathrm{~m}$; paso Maillén, entre punta Panitao y punta Puchegui, $22 \mathrm{~m}$; bahía de Ancud, SE de punta Ahuí, $8 \mathrm{~m}$; archipiélago de Chiloé, paso Tenaun, $\mathrm{S}$ de punta Tenaun, $70 \mathrm{~m}$ (Lund University Chile Expedition St. M131: 20¹3'10" S, 70¹0'19” O, St. M127:

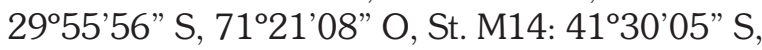

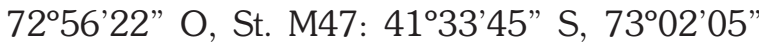
O, St. M98: 4150'10” S, 7351'20” O, St. M42: 42²0'50” S, 73²2' O, Wesenberg-Lund, 1962). Golfo Corcovado, E de isla Puduhuapi, $190 \mathrm{~m}$ (Expedición MarChile I St. X1: 4257' S, 7257’ O, Hartmann-Schröder, 1965). Seno Última Esperanza (51 $70^{\prime} \mathrm{S}, 72^{\circ} 46^{\prime} \mathrm{O}$ ); isla Dawson, cabo Valentín (53⒉ ' S, 7040' O), 274 m, y bahía Harris (5350' S, 70²4' O), 27 m, estrecho de Magallanes (Ehlers, 1900). Canal Beagle (Swedish Antarctic Expedition St. 61: 5454' S, 6752' O, Hartman, 1953).

Distribución: sector antártico occidental; Japón (Orensanz, 1976); Chile: desde Iquique (20¹3'10" S) hasta el canal Beagle (5454' S).

\section{Syllis tamarae}

Álvarez-Campos \& Verdes, 2017

Syllis tamarae Álvarez-Campos \& Verdes, 2017, pp. 6-7, figs. 6-8, 14-18.

Localidad tipo: playa Las Cruces (3330' S, 71³9' O), Chile central.

Distribución: hasta ahora conocida sólo en la localidad tipo, en Chile central.

\section{Syllis tripantu}

Álvarez-Campos \& Verdes, 2017

Syllis tripantu Álvarez-Campos \& Verdes, 2017, pp. 7-8, figs. 4, 5, 19-29.

Localidad tipo: playa Las Cruces (3330' S, 71³9’ O), Chile central.

Distribución: hasta ahora conocida sólo en la localidad tipo, en Chile central.

\section{Syllis valida Grube, 1857}

Syllis valida Grube, 1857, pp. 183-184. Typosyllis valida: Licher, 1999, p. 211, 
lám. 90.

Localidad tipo: Valparaíso $\left(33^{\circ} 02^{\prime}\right.$ S), Chile central.

Otra referencia para Chile: WesenbergLund, 1962, p. 58 (sólo se cita).

Distribución: hasta ahora conocida sólo en la localidad tipo, en Chile central.

60. Syllis variegata Grube, 1860

Syllis variegata Grube, 1860, pp. 85-86, lám. 3, fig. 6.

Localidad tipo: Croacia, mar Adriático.

Referencias para Chile: Ehlers, 1897, pp. 37-38; 1900 , p. 212; 1901b, p. 86. Syllis (Typosyllis) variegata: Wesenberg-Lund 1962 , pp. 53-54. Typosyllis variegata: Hartman 1964, p. 96, lám. 29, figs. 8-9.

Localidades de registro en Chile: Antofagasta, intermareal; Montemar, $\mathrm{N}$ de Valparaíso, "Estación de Biología Marina", intermareal; estero Reloncaví, bahía Ralún, 35-40 $\mathrm{m}$; seno Reloncaví, isla Tenglo, intermareal; seno Reloncaví, paso Maillén, entre punta Panitao y punta Puchegui, $22 \mathrm{~m}$; bahía de Ancud, $\mathrm{O}$ de Rocas Amazonas, $40 \mathrm{~m}$ (Lund University Chile Expedition St. M159: 2339' S, 70²5' O, St. M123: 3257'24" S, 71'33'25" O, St. M29:

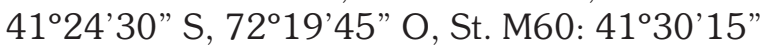

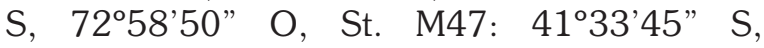
7302'05" O, St. M94: 4146'30" S, 7345'45" O, Wesenberg-Lund, 1962). Isla Dawson (5400' S), punta San Valentín, 274 m, y bahía Harris, 27 $\mathrm{m}$, estrecho de Magallanes (Ehlers, 1900). Punta Arenas (5310' S), estrecho de Magallanes, 24 m; isla Navarino, $\mathrm{O}$ de puerto Pantalón (55 $03^{\prime} \mathrm{S}$ ), canal Beagle (Ehlers, 1897).

Distribución: océano Atlántico; océano Pacífico; océano Indico; mar Mediterráneo; Nueva Zelanda (Knox, 1951); Australia (Hartmann-Schröder, 1984); islas Galápagos (Westheide, 1974); Chile: desde Antofagasta

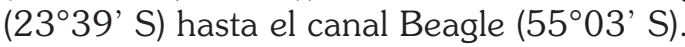

\section{Género Trypanedenta}

Imajima \& Hartman, 1964

Trypanosyllis (Trypanedenta) Imajima \& Hartman, 1964, p. 125.
Solamente hay una especie de este género en Chile, que ha sido citada casi siempre como Trypanosyllis. Tras la revisión de ÁlvarezCampos et al. 2017, ha sido trasferida a Trypanedenta, elevando este taxón de nivel subgenérico al de género.

\section{Trypanedenta gigantea}

(McIntosh, 1885)

Syllis gigantea McIntosh, 1885, pp. 193195, lám. 30, figs. 1-3, lám. 33, fig. 4, lám. 15A, fig. 14, lám. 34A, fig. 7.

Trypanosyllis gigantea: Ehlers, 1897, pp. 35-36.

Trypanedenta gigantea: Álvarez-Campos et al. 2017, p. 519, figs. 6 G-I, 9.

Localidad tipo: frente a las islas Kerguelen, 18-182 m.

Referencias para Chile: Trypanosyllis gigantea: Ehlers, 1897: 35-36; 1900: 212; 1901a: 257; 1901b: 85; Fauvel, 1941: 278; Wesenberg-Lund, 1962: 60-61 (sólo se cita).

Localidades de registro a lo largo de la costa de Chile y el archipiélago Juan Fernández: Punta Arenas (5310' S), estrecho de Magallanes, $14 \mathrm{~m}$ (Ehlers, 1901a). Seno Última Esperanza (51 ${ }^{\circ} 70^{\prime}$ S), $12-18 \mathrm{~m}$; bahía Inútil (5330' S), 36-54 m; punta San Valentín (54 $\left.00^{\circ} \mathrm{S}\right), 274 \mathrm{~m}$, y bahía Harris, 27 m, isla Dawson; río Cóndor (5400' S), costa E del canal Whiteside (Ehlers, 1900). Punta Arenas (5310' S), estrecho de Magallanes; canal Beagle (Ushuaia, 5449'S), 1,8-3,6 m (Ehlers, 1897). Bahía Orange $\left(55^{\circ} 10^{\prime} \mathrm{S}\right)$, isla Hoste, península Hardy (Fauvel, 1941). Archipiélago Juan Fernández, 27-36 m (Ehlers, 1901a).

Distribución: mar Mediterráneo (?); océano Indico, islas Nicobar; sur de Australia; Nueva Zelanda; islas Falkland (Malvinas); islas subantárticas; Antártida; Chile: desde seno Última Esperanza (51 $70^{\prime}$ S) hasta isla Hoste (55¹0’ S) y archipiélago Juan Fernández.

Género Trypanosyllis (Claparède, 1864)

Trypanosyllis Claparède, 1864, p. 558

Dos especies asignadas a este género han sido citadas para la costa de Chile y el archipiélago Juan Fernández. 
Clave para las especies del género Trypanosyllis registradas en Chile

1a Cirros dorsales cortos, con pocos artejos (6-7); artejos de las sedas compuestas con el diente proximal pequeño

T. parazebra Hartmann-Schröder, 1965 $1 \mathrm{~b}$ Cirros dorsales largos; artejos de las sedas compuestas con ambos dientes bien desarrollados, casi iguales T. zebra (Grube, 1860) Como no parece haber diferencias morfológicas claras entre Trypanosyllis taeniaformis (Haswell) y $T$. zebra, provisionalmente las consideramos sinónimas.

\section{Trypanosyllis parazebra}

Hartmann-Schröder, 1965

Trypanosyllis parazebra HartmannSchröder, 1965: 289-291, figs. 289-292. de Chile

Localidad tipo: Arica (18 $\left.28^{\prime} \mathrm{S}\right), 1 \mathrm{~m}$, norte

Distribución: hasta ahora conocida sólo en Chile en la localidad tipo, en el norte de Chile.

63. Trypanosyllis zebra (Grube, 1860)

Syllis zebra Grube, 1860, p. 86.

Trypanosyllis zebra: Langerhans, 1879, p. 556.

Localidad tipo: Francia (Mediterráneo).

Referencia en Chile: Trypanosyllis taeniformis (Haswell) in Wesenberg-Lund 1962, p. 61.

Localidades de registro en Chile: canal de Chacao y golfo de Ancud, 8-70 m; golfo de Ancud, entre punta Abtao e isla Abtao, $36 \mathrm{~m}$; O de Rocas Amazonas, $\mathrm{N}$ de la bahía de Ancud, 40 m; bahía de Ancud, SE de punta Ahuí, $8 \mathrm{~m}$; archipiélago de Chiloé, paso Tenaun, $\mathrm{S}$ de punta Tenaun, 70 $\mathrm{m}$ (Lund University Chile Expedition St. M106:

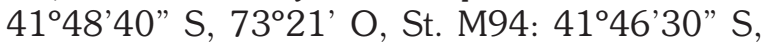
7345'45" O, St. M98: 4150'10" S, 7351'20" O, St. M42: 42²0'50” S, 73²2' O, WesenbergLund, 1962).

Según Imajima \& Hartman (1964, p. 128) la identidad con la especie de Haswell es dudosa.

Distribución: la especie de Haswell se distribuye en áreas tropicales del Pacífico e Indico (Capa, San Martín \& López, 2001); la especie determinada por Wesenberg-Lund (1962) se distribuye en Chile en el canal de Chacao y el golfo de Ancud.

\section{RESUMEN}

El listado de especies de Syllidae a lo largo de la costa de Chile, incluidas las aguas interiores en el área de fiordos y canales australes, y en sus islas oceánicas (isla de Pascua y archipiélago Juan Fernández), incluye un total de 63 especies, distribuidas de la siguiente manera:

- En la subfamilia Anoplosyllinae, hay una especie del género Anoplosyllis, y dos de Syllides. Syllides japonica es una especie ampliamente repartida por el océano Pacífico, pero también citada en otras áreas. Una revisión detallada de ejemplares de distintas partes del mundo podría evidenciar la existencia de un conjunto de especies.

- De la subfamilia Autolytinae se han registrado dos especies del género Epigamia, aunque su pertenencia a este género es discutible, una de Myrianida, de asignación genérica también disutible, y una de Proceraea.

- De la subfamilia Exogoninae se han registrado tres especies del género Salvatoria, de las cuales la presencia de S. limbata es dudosa, ya que se trata de una especie de las costas europeas; cuatro especies que asignamos al género Prosphaerosyllis, pero habría que revisar con detalle el material tipo para mayor seguridad; cuatro especies de Erinaceusyllis dos de las cuales las asignamos provisionalmente a este género, pues sería necesario una revisión del material tipo y redescripciones adecuadas; tres especies de Sphaerosyllis, de las cuales $S$. hystrix resulta una cita dudosa, ya que es una especie de las costas europeas, y se 
han descrito varias especies de este género en todo el mundo con las características glándulas en bastoncillos, que anteriormente se creían exclusivas de tal especie; una especie de Parapionosyllis, cuatro de $\mathrm{Pa}$ rexogone, y otras cuatro de Exogone, de las cuales $E$. verugera resulta dudosa.

- De la subfamilia Syllinae, hay una sola especie del género Haplosyllis, registrada en isla de Pascua, pero que resulta altamente dudosa, ya que esa especie, $H$. spongicola, parece estar restringida a las costas europeas y del Mediterráneo; una especie de Trypanedenta; dos de Trypanosyllis, si bien la especie $T$. zebra resulta dudosa, ya que es una especie de aguas europeas $y$, como demostraron Álvarez-Campos et al. (2017), hay un elevado número de especies similares repartidas por todos los mares, con distribuciones mas reducidas; una especie de Branchiosyllis, y 19 de Syllis, de las que cuatro resultan dudosas por las mismas razones que las anteriores, $S$. cornuta, $S$. hyalina, S. variegata y $S$. prolifera.

- De los géneros considerados como Incertae Sedis por Aguado \& San Martín (2009, 2012), hay una especie de Amblyosyllis, una de Brachysllis, dos de Paraehlersia, de las que la presencia de $P$. ferrugina resulta dudosa, por las mismas razones que en los casos anteriores, así como una especie de Neopetitia, que muy posiblemente no se trate de $N$. amphophthalma, al igual que las anteriores especies dudosas .

Todas estas especies que consideramos de presencia dudosa provienen de la "visión europeista" de los investigadores de finales del siglo XIX y gran parte del siglo XX (Elías et al. 2017), hasta épocas relativamente recientes. Ciertamente, los ejemplares de esas especies provenientes de localidades chilenas deberían pasar por una revisión crítica.

\section{GLOSARIO DE TÉRMINOS UTILIZADOS EN LAS CLAVES}

Acículas: ejes quitinosos robustos que soportan internamente cada rama parapodial donde estas se proyectan desde el cuerpo.
Acículas acuminadas: acículas que se aguzan abruptamente.

Ápodo: segmento desprovisto de parápodos.

Aqueto: segmento desprovisto de sedas.

Artejos: una parte o sección demarcada por una articulación de una seda o un cirro; dentro de los artejos de los cirros de los sílidos pueden encontrarse glándulas.

Artejos falcígeros: la parte distal u hoja de una seda compuesta, corta, robusta y terminada en punta curva, como gancho.

Átoco: organismo no maduro sexualmente, cuyo cuerpo no ha sufrido ningún cambio morfológico asociado con la reproducción.

Cirróforo: Pieza basal de un cirro sobre la que se articula el cirrostilo.

Cirrostilo: Pieza distal de un cirro articulada sobre el cirróforo.

Epigamia: modificación estructural de un individuo adulto completo hacia un estado reproductor o epítoco.

Epítoco: poliqueto que se encuentra en la fase de epitoquia.

Epitoquia: fase por la que atraviesan algunos poliquetos en el momento de la reproducción, y que se caracteriza por transformaciones morfológicas, fisiológicas y ecológicas notables.

Escisiparidad: una forma de esquizogamia común en los sílidos en que los estolones se desarrollan de segmentos ya existentes.

Espinígeras: seda compuesta cuya hoja (artejo) es alargada y terminada en punta fina.

Esquizogamia: en términos generales es una forma de reproducción asexual que involucra fisión que lleva a la formación de dos o más individuos; en poliquetos corresponde a una modificación estructural del adulto que lleva a la formación asexual de estolones sexuados.

Estolón: individuo reproductor desarrollado a partir de un grupo de segmentos corporales del progenitor, o a partir de yemas.

Estolonización: tipo de reproducción asexual con formación de estolones sexuados, que ocurre en los sílidos.

Falcígeros: seda compuesta cuya hoja (artejo) es generalmente corta, robusta y distalmente recurvada, que puede terminar en una punta unidentada o bidentada. 
Faringe inerme: la faringe desprovista de cualquier estructura dura, como dientes, trépano, etc ....

Gemiparidad: reproducción asexual que implica la formación de en forma de cadena o racimos de estolones (= Estolinización).

Moniliforme: con la apariencia de un collar de cuentas; formado de artejos redondeados; se refiere a formado por artejos sucesivos como el cirro parapodial dorsal en algunos sílidos.

Órganos nucales: órganos sensoriales ubicados en el lado posterodorsal de la cabeza y diversamente desarrollados.

Proventrículo: órgano muscular $y$ glandular, estriado transversalmente, con forma de barril ubicado posterior a la faringe característico de los sílidos.

Trépano: parte quitinizada, anteriormente dentada de la faringe de algunos poliquetos, especialmente los sílidos.

\section{AGRADECIMIENTOS}

Agradecemos al Dr. Eulogio Soto, Profesor de la Escuela de Biología Marina, Facultad de Ciencias del Mar y de Recursos Naturales, Universidad de Valparaíso, por la acogida y organización del "Curso avanzado de taxonomía y ecología de Syllidae", realizado en la escuela de Biología Marina, del 10 al 14 de diciembre de 2012, durante el cual surgió la idea de escribir este trabajo.

Nuestros agradecimientos a dos evaluadores anónimos que hicieron importantes correcciones y valiosas sugerencias para mejorar nuestro trabajo.

A la Dra. (C) Valeria Espinoza, Pontificia Universidad Católica de Chile, por su ayuda en la preparación de la Figura 1 y la revisión previa de los datos.

También agradecemos al Proyecto Fauna Ibérica (Museo Nacional de Ciencias Naturales, Madrid, España), por permitirnos reproducir las figuras incluidas en este trabajo.

Este trabajo fue financiado parcialmente con los aportes de Faunamar Ltda.

\section{BIBLIOGRAFÍA}

Aguado, M. T., \& San Martín, G. (2008). Re- description of some enigmatic genera of Syllidae (Phyllodocida: Polychaeta). Journal of the Marine Biological Association of the United Kingdom, 88(1), 35-56.

Aguado, M. T., \& San Martín, G. (2009). Phylogeny of Syllidae (Annelida, Phyllodocida) based on morphological data. Zoologica Scripta, 38(4), 379-402.

Aguado, M. T., San Martín, G.', \& Ten Hove, H. (2008). Syllidae (Annelida: Polychaeta) from Indonesia collected by the Siboga (18991900) and Snellius (1984) expeditions. Zootaxa, 1673, 1- 48.

Aguado, M. T., San Martín, G., \& Siddall, M. T. (2012). Systematics and evolution of syllids (Syllidae, Annelida). Cladistics, 28, 234230.

Aguado, M. T., Nygren, A., \& Siddall, M. E. (2007). Phylogeny of Syllidae (Polychaeta) based on combined molecular analysis of nuclear and mitocondrial genes. Cladistics, 23, 552-564.

Álvarez-Campos, P. \& Verdes, A. (2017). Syllids inhabiting holdfast of Lessonia spicata in Central Chile: diversity, systematics, and description of three new species. Systematics and Biodiversity, 1-12.

Álvarez-Campos, P., Giribet, G., San Martín, G., Rouse, G., \& Riesgo, A. (2017) . Straightening the striped chaos: systematics and evolution of Trypanosyllis and the case of its pseudo-cryptic type species Trypanosyllis khronii (Annelida, Syllidae). Zoological Journal of the Linnean Society, 179, 492540.

Álvarez-Campos, P., Taboada, S., San Martín, G., Leiva, C., \& Riesgo, A. (En prensa). Phylogenetic relationships within flattened syllids (Annelida, Syllidae). One new genus and five new species. Invertebrate Systematics.

Amoureux, L. (1977). Annélides polychètes errantes recueillies sur les pentes du talus continental, à l'entrée de la Manche, avec description de deux espèces nouvelles. Campagne 1973 de la Thalassa. Cahiers de Biologie Marine, 18, 391- 411.

Augener, H. (1913). Polychaeta I, Errantia. In: Michaelsen, W. \& R. Hartmeyer (Eds.): Die Fauna südwest-Australiens. Ergebnisse 
der Hamburger Südwest-australischen Forschungsreise 1905, 4(5), 65-304, 2 pls. Augener, H. (1918). Polychaeta. In: Michaelsen, W. (Ed.): Beiträge zur Kenntnis des Meeresfauna West-Afrikas, 2(2), 67-625, 6 pls.

Augener, H. (1922). Litorale Polychaeten von Juan Fernández. In: C. Skottsberg (Ed.): The Natural History of Juan Fernández and Easter Island, 3, 161-218, 1 lám.

Barroso, R., de Paiva, P. C., Nogueira, J. M. M., \& Fukuda, M. V. (2017). Deep sea Syllidae (Annelida, Phyllodocida) from Southwestern Atlantic. Zootaxa, 4221(4), 401-430.

Beesley, P. L., Ross, G. J. B., \& Glasby, C. J. (Eds). (2000). Polychaetes \& Allies: The Southern Synthesis. Fauna of Australia. Vol. 4. Polychaeta, Myzostomida, Pogonophora, Echiura, Sipuncula. CSIRO Publishing: Melbourne, 465 pp.

Blanchard, E. (1849). Anelides. In: Gay's Historia física y politica de Chile. Zoología, 3, 9-52, pls. 1, 2.

Bremec, C., Elías, R., \& Gambi, M. C. (2000). Comparison of the polychaete fauna composition from the Patagonian Shelf and the Strait of Magellan. Preliminary results from cruises Shinkai Maru IV, V, X, and XI (1978-1979) and Second Italian Oceanographic Cruise (1991). Bulletin of Marine Science, 67(1), 189-197.

Brusa, V. S., Aguado, M. T., San Martín, G., \& Rouse, G. (2013). Revision of the genus Eusyllis Malmgren, 1867 (Annelida: Phyllodocida: Syllidae: Eusyllinae), with the description of a new species from the eastern Pacific Ocean. Zootaxa, 3599(1), 37-50.

Capa, M., San Martín, G., \& Lopéz, E. (2001). Autolytinae, Eusyllinae y Exogoninae (Syllidae: Polychaeta) del Parque Nacional de Coiba, Panamá. Revista de Biología Tropical, 49(2), 621-628.

Claparède, E. (1863). Bebachtungen über Anatomie und Entwicklungsgeschichte wirbelloser Thiere and der Küste von Normandie angestellt. Leipzig. VII+ 120 pp., 18 pls.

Claparède, E. (1864). Glanures zootomiques parmi les annélides de Port-Vendres (Pyrénées Orientales). Mémoires de la Société de Physique et d'Histoire Naturelle de Genève, 17(2), 463-600, pls. 1-8.

Claparède, E. (1868). Les Annélides Chétopodes du Golfe de Naples. Mémoires de la Societé de Physique et d' Histoire Naturelle de Géneve, 19(2), 313-584, pls. 1-16.

Day, J. H. (1954). The Polychaeta of Tristan da Cunha. Norwegian Scientific Expedition to Tristan da Cunha 1937-1938, Report 29, 1-35.

Day, J. H. (1967). A monograph on the Polychaeta of Southern Africa. British Museum Natural History Publication, 656, 878 pp.

Díaz-Díaz, O., \& Ríos, B. (2015). First record of Proceraea anopla (Monro, 1933) (Syllidae: Autolytinae) from Venezuelan coast. PanAmerican Journal of Aquatic Sciences, 9 (2), 150-153.

Ehlers, E. (1864). Die Borstenwürmer, nach systematischen und anatomischen Undersuchungen dargestellt. Leipzig, pp. 1-268, pls. 1-11.

Ehlers, E. (1887). Reports on the results of dredging, under the direction of $\mathrm{L}$. F. Pourtalès, during the years 1868-1870, and of Alexander Agassiz, in the Gulf of Mexico (1877-78), and in the Caribbean Sea (1878-79), in the U.S. Coast Survey steamer "Blake", Lieut-Com. C. D. Sigsbee, U.S.N. and Commander J. R. Bartlett, U.S.N., commanding. XXXI. Report on the Annelids. Memoirs of the Museum of Comparative Zoology at Harvard College, 15 , vi \& 335 pp.

Ehlers, E. (1897). Polychaeten. Hamburger Magalhaenischen Sammelreise. Hamburg, 148 pp., 9 pls.

Ehlers, E. (1900). Magellanische Anneliden gesammelt während der schwedischen Expedition nach den Magellansländern. Festschrift zur Feier des Hundertfünfzigjährigen Bestehens der Königlichen Gesellschaft der Wissenschaften zu Göttingen, 1900, 206223.

Ehlers, E. (1901a). Die Anneliden der Sammlung Plate. Fauna Chilensis. Zoologische 
Jahrbücher Jena, Suppl., 5, 251-272.

Ehlers, E. (1901b). Die Polychaeten des magellanischen und chilenischen Strandes. Ein faunistischer Versuch. Festschrift zur Feier des Hundertfünfzigjährigen Bestehens der Königlichen Gesellschaft der Wissenschaften zu Göttingen, 232 pp., 25 pls.

Ehlers, E. (1908). Wissenschaftliche Ergebnisse der deutschen Tiefsee-Expedition auf dem Dampfer Valdivia 1898-1899. Im Auftrage des Reichsamtes des Innern, herausgegeben von Carl Chun, Professor der Zoologie in Leipzig, Leiter der Expedition, vol. 16, Lief. 1. Die Bodensässigen Anneliden aus den Sammlngen der deutschen TiefseeExpedition. Jena, Gustav Fischer. Pp. 1-168, 23 pls.

Ehlers, E. (1912). Polychaeta. National Antarctic Expedition 1901-1904. Trustees of the British Museum, Natural History, Zoology, London, 6, 1-32, 3 pls.

Ehlers, E. (1913). Die Polychaeten-Sammlungen der deutschen Südpolar-Expedition 19011903. Deutsche Südpolar-Expedition, 13(4), 397-598, pls. 26-46.

Elías, R., Jaubet, M. L., Ferrando, A., \& Saracho, M. A. (2017). Historia y perspectivas de los estudios sobre poliquetos en Argentina. En O. Díaz-Díaz, D. Bone, C. T. Rodríguez \& V. H. Delgado-Blas (Eds.), Poliquetos de Sudamérica (pp, 3-23). Volumen especial del Boletín del Instituto Oceanográfico de Venezuela. Cumaná, Venezuela.

Fauchald, K., \& Jumars, P. A. (1979). The diet of worms: a study of polychaete feeding guilds. Oceanography and Marine Biology Annual Review, 17, 193-284.

Fauvel, P. (1923). Polychètes errantes. Faune de France. Le Chevalier eds., Paris, 5.

Fauvel, P. (1936). Polychètes Expédition antarctique Belgica. Résultats du voyage de la Belgica en 1987-1899, sous le commandement de A. de Gerlache de Gomery, 46 pp., 1 lám.

Fauvel, P. (1941). Annélides polychètes de la Mission du Cap Horn (1882-1883). Bulletin du Muséum national d'Histoire Natural, Paris, sér. 2, 13(4), 272-298.
Gambi, M. C., \& Mariani, S. (1999). Polychaetes of the soft bottoms of the Straits of Magellan collectes during the Italian oceanographic cruise in February-March 1991. Scientia Marina, 63(Suppl. 1), 233-242.

Gardiner, S. L. (1975). Errant polychaete annelids from North Carolina. Journal of the Elisa Mitchell Scientific Society, 91(3), 77-220.

Glasby, C. J. (2000). Family Syllidae. En P. L. Beesley, G. J. B. Ross \& C. J. Glasby (Eds.), Polychaetes and Allies: The Southern Synthesis. Fauna of Australia. Vol. 4: Polychaeta, Myzostomida, Pogonophora, Echiura, Sipuncula (pp. 161-167). CSIRO Publishing, Melbourne, Victoria.

Glasby, C. J., Schroeder, P. C. \& Aguado, M. T. (2012). Branching out: a remarkable new branching syllid (Annelida) living in a Petrosia sponge (Porifera: Demospongiae). Zoological Journal of the Linnean Society, 164, 481-497.

Gravier, C. (1906). Expédition Antarctique française (1903-1905) commandeé par le Dr. Jean Charcot. Science naturelles: documents scientifiques. Vers. Annélides polychètes. Paris, Masson et Cie., 1, 1-75, 5 pls.

Grube, A. E. (1850). Die Familien der Anneliden. Archiv für Naturgeschichte, 16(1), 249364.

Grube, A. E. (1857). Annulata Oerstediana, etc. Pt. 2. Videnskabelige Meddelelser fra Dansk Naturhistorisk Forening I Københaun , 1857, 158- 186.

Grube, A. E. (1860). Beschreibungen neuer oder wenig bekannter Anneliden. Archiv für Naturgeschichte, 26(1), 71-118, pls. 3-5.

Hartman, O. (1953). Non-pelagic Polychaeta of the Swedish Antarctic Expedition 19011903. En Further Zoological Results of the Swedish Antarctic Expedition 19011903, 4(2), 1-83.

Hartman, O. (1959). Catalogue of the Polychaetous Annelids of the world. Parts I and II. Allan Hancock Foundation Publications Occasional Papers, 23, 1-628.

Hartman, O. (1964). Polychaeta Errantia of Antarctica. Antarctic Research Series, 3, 1-131. 
Hartman, O. (1967). Polychaeta Annelids collected by the USNS Eltanin and Staten Island Cruises, chiefly from Antarctic Seas. Allan Hancock Monographies on Marine Biology, 2, 1-387.

Hartmann-Schröder, G. (1962). Zur Kenntnis des Eulitorals der chilenischen Pazifikküste und der argentinischen Küste Südpatagoniens unter besonderer Berücksichtigung der Polychaeten und Ostracoden. Tl. II. Die Polychaeten des Eulitorals. Mitteilungen aus dem Hamburgischen Zoologischen Museum und Institut , 60 (Suppl.), 57-167.

Hartmann-Schröder, G. (1965). Zur Kenntnis des Sublitorals der chilenischen Küste unter besonderer Berücksichtigung der Polychaeten und Ostracoden. Tl. II. Die Polychaeten des Sublitorals. Mitteilungen aus dem Hamburgischen Zoologischen Museum und Institut, 62 (Suppl.), 59-305.

Hartmann-Schröder, G. (1974). Zur Kenntnis des Eulitorals der afrikanischen Westküste zwischen Angola und Kap der Guten Hoffnung und der afrikanischen Ostküste von Südafrika und Mocambique unter besonder Berücksichtigung der Polychaeten und Ostracoden. Die Polychaeten des Untersuchungebietes. Mitteilungen aus dem Hamburgischen Zoologischen Museum und Institut, 69, 95-228.

Hartmann-Schröder, G. (1979). Die Polychaeten der tropischen Nordwestküste Australiens (zwischen Derby im Norden und Port Hedland im Süden). Teil 2. IN: HartmannSchröder, G. and Gerd Hartmann. Zur Kenntnis des Eulitorals der australischen Küsten unter besonder Berücksichtigung der Polychaeten und Ostracoden. Mitteilungen aus dem Hamburgischen Zoologischen Museum und Institut, 76, 77-218.

Hartmann-Schröder, G. (1984). Teil 10. Die Polychaeten der antiborealen Südküste Australiens (Zwischen Albany im Westen und Ceduna im Osten). In: HartmannSchröder, G. \& G. Hartmann: Zur Kenntnis des Eulitorals der australischen Küsten unter besonderer Berücksichtigung der Polychaeten un Ostracoden. Mitteilungen aus dem Hamburgischen Zoologischen
Museum und Institut, 81, 7-62.

Hartmann-Schröder, G. (1989). Die polychaeten der antiborealen und subtropisch-tropischen Küste Südost-Australiens zwischen Lakes Entrance (Victoria) im Süden und Maclean (New South Wales) im Norden IN: HartmannSchröder, G. and Gerd Hartmann, Zur Kenntnis des Eulitorals der australischen Küsten unter besonderer Berucksichtigung der Polychaeten und Ostracoden. Teil 14. Mitteilungen aus dem Hamburgischen Zoologischen Museum und Institut, 86, 11-63.

Hartmann-Schröder, G. (1991). Beitrag zur Polychaetenfauna der Bahia Quillaipe (SüdChile). Helgoländer Meeresforschungen, 45, 39-58.

Hartmann-Schröder, G., \& Rosenfeldt, P. (1988). Die Polychaeten der "Polarstern"-Reise ANT III/2 in die Antarktis 1984. Teil 1. Euphrosinidae bis Chaetopteridae. Mitteilungen aus dem Hamburgischen Zoologischen Museum und Institut, 85, 25-72.

Haswell, W. A. (1920). Australian Syllidae, Eusyllidae and Autolytidae. Proceedings of the Linnean Society of New South Wales, 45, 90-112, pls. 10-13.

Hutchings, P. A., \& Murray, A. (1984). Taxonomy of polychaetes from the Hawkesbury River and the Southern estuaries of New South Wales, Australia. Records of the Australian Museum, Suppl. 3, 1-118.

Imajima, M. (1966a). The Syllidae (Polychaetous Annelids) from Japan (III). Eusyllinae. Publications of the Seto Marine Biological Laboratory, 14, 85-116.

Imajima, M. (1966b). The Syllidae (Polychaetous Annelids) from Japan (IV). Syllinae (1). Publications of the Seto Marine Biological Laboratory, 14(3), 219-252.

Imajima, M., \& Hartman, O. (1964). The Polychaetous annelids of Japan, Part I. Allan Hancock Foundation Publications, Occasional Paper, 26, 1-452.

Jiménez, M., San Martín, G., \& López, E. (1994). Redescriptions of Pionosyllis neapolitana Goodrich, 1930 and Pionosyllis nutrix Monro, 1936, referred to the genus 
Grubeosyllis Verrill, 1900 (Polychaeta, Syllidae, Exogoninae). Polychaete Research, 16, 52-55.

Knox, G. A. (1951). A guide to the families and genera of New Zealand polychaetes. Tuatara, 4(2), 63-85.

Knox, G. A., \& Cameron, D. B. (1970). Polychaeta from the Snares Islands, New Zealand. Transactions of the Royal Society of New Zealand, Biological Sciences, 12(9), 7385.

Kohn, A. J., \& Lloyd, M. C. (1973). Marine Polychaete Annelids of the Easter Island. International Review of Hydrobiology, 58(5), 691-712.

Krohn, A. (1852). Ueber die Erscheinungen bei der Fortpflanzung von Syllis prolifera und Autolytus prolifer. Archiv für Naturgeschichte, 18, 66-76.

Lamarck, J. B. (1818). Histoire Naturelle des animaux sans vertebrés, presentant les caractères generaux et particuliers de ces animaux, leur distribution, leurs classes, leurs familles, leurs genres, et la citation des principales espèces qui s'y rapportent; precedes d'une introduction offrant la détermination des caractères essentiels de l'animal, sa distinction du vegetal et des autres corps naturelles, enfin l'exposition des príncipes fondamentaux de la zoologie. Deterville Paris, 5, 612.

Langerhans, P. (1879). Die Wurmfauna von Madeira. Zeitschrift für Wissenschaftliche Zoologie, 32, 513-592, pls. 31-33.

Langerhans, P. (1881). DieWurmfaunavonMadeira. III. Zeitschrift für Wissenschaftliche Zoologie, 34, 87-143, pls. 4-6.

Lattig, P., \& Martin, D. (2009). A Taxonomic revision of the genus Haplosyllis Langerhans, 1887 (Polychaeta: Syllidae: Syllinae). Zootaxa, 2220, 1-40.

Lattig, P., San Martín, G., \& Martin, D. (2007). Taxonomic and morphometric analyses of the Haplosyllis spongicola complex (Polychaeta: Syllidae: Syllinae) from Spanish seas, with the re-description of the typespecies and descriptions of two new species. Scientia Marina, 71(3), 551-570.

Laubier, L. (1967). Quelques Annélides Polychètes interstitielles d'une plage de Cote D'Ivoire. Vie et Milieu, 18(3A), 573-594.

Lee, M. R., Castilla, J. C., Fernández, M., Clarke, M., González, C., Hermosilla, C., Prado, L., Rozbaczylo, N., \& Valdovinos, C. (2008). Free-living benthic marine invertebrates in Chile. Revista Chilena de Historia Natural, 81, 51-67.

Licher, F. (1999). Revision of Gattung Typosyllis Langerhans, 1879 (Polychaeta: Syllidae). Morphologie, Taxonomie und Phylogenie. Abhandlungen der Senckenbergischen Natursforchenden Gesellschaft, 551, $1-336$.

Liñero-Arana, I., \& Díaz Díaz, O. (2011). Poliquetos de Venezuela I: Aspectos biológicos y ecológicos. Editorial Universitaria, CumanáVenezuela.

Malaquin, A. (1893). Recherches sur les syllidiens. Mémoires de la Société des Sciences, de l'Agriculture et des Arts de Lille 4ème série, 18, 1-477.

Malmgren, A. J. (1867a). Annulata Polychaeta Spetsbergiae, Groenlandiae, Islandiae et Scandinaviae hactenus cognita. Ofversigt af Svenska Vatenskaps Academiens Förhandlinger., 1-127, pls. 1-14.

Malmgren, A. J. (1867b). Annulata Polychaeta Spetsbergiae, Groenlandiae, Islandiae et Scandinaviae hactenus cognita. Ofversigt af Svenska Vatenskaps Academiens Förhandlinger, 24, 127-235, pls. 2-15.

Martin, D., Britayev, T. A., San Martín, G., \& Gil, J. (2003). Inter-population variability and character description in the sponge associated Haplosyllis spongicola complex (Polychaeta: Syllidae). Hydrobiologia, 496, 145-162.

Mesnil, F., \& Caullery, M. (1918). Sur l'organisation et la biologie d'un syllidien Exogone (Parexogone n. s.g.) hebes Webster \& Benedict, var. hibernica Southern, habitant un sable compacte. Bulletin de la Société Zoologique de la France, 42, 126-132.

Milne-Edwards, A. (1845). Observations sur le développment des Annélides. Annales des Sciences Naturelles Paris, 3, 145-182.

McIntosh, W. C. (1885). Report on the Annelida Polychaeta collected by H.M.S. Challenger 
during the years 1873-1876. Challenger Reports, 12, 1-554, pls. 1-55, and 1a-39a. Monro, C. C. A. (1936). Polychaete worms. II. Discovery Reports, 12, 59-198.

Monro, C. C. A. (1939). Polychaeta. Antarctic Research Expedition 1929-1931. B.A.N.Z.A.R.E. Reports, series B (Zoology and Botany), 4(4), 87-156.

Nogueira, J. M. M., \& San Martín, G. (2002). Species of Syllis Savigny in Lamarck, 1818 (Polychaeta: Syllidae) living in corals in the State of Sao Paulo, southeastern Brazil. Beaufortia, 52(7), 57-93.

Nygren, A. (2004). Revision of Autolytinae (Syllidae: Polychaeta). Zootaxa, 680, 1-314.

Ørsted, A. S. (1845a). Ueber die Entwicklung der Jungen bei einer Annelide und über ausseren Unterschiede zwischen beiden Geschlechten. Archiv für Naturgeschichte, 11(1), 20-23, lám. 2.

Ørsted, A. S. (1845b). Fortgenelse over Dyr, samlede i Christianiafjord ved Drøbak fra 21-24 Juli, 1844. Naturh. Tidskr. Koben., ser. 2, 1, 403-415, pl. 5.

Orensanz, J. M. (1976). Los Anélidos Poliquetos de la Provincia Biogeográfica Magallánica. I. Catálogo de las especies citadas hasta 1974. Laboratorio de Comunidades Bentónicas, Santa Clara del Mar. Contribución Técnica, 1, 1-83.

Palma, M., Quiroga, E., Gallardo, V. A., Arntz, W. E., Gerdes, D. , Schneider, W., \& Hebbeln, D. (2005). Macrobenthic animal assemblages of the continental margin off Chile $\left(22^{\circ}\right.$ to $\left.42^{\circ} \mathrm{S}\right)$. Journal of the Marine Biological Association of the United Kingdom, 85, 233-245.

Pettibone, M. H. (1963). Marine polychaete worms of the New England region, 1: Aphroditidae through Trochochetidae. Bulletin of the U.S. National Museum, 227, 1-356.

Rathke, H. (1843). Beiträge zur Fauna Norwegens. Nova Acta Academie Caesareae Leopoldino-Carolinae Germanicum Naturae Curiosorum , 20(1), 1-264, pls. 1-12.

Rozbaczylo, N. 1985. Los Anélidos Poliquetos de Chile. Indice Sinonímico y Distribución Geográfica de Especies. Monografías
Biológicas, 3, 1-284.

Rozbaczylo, N. \& Moreno, R. A. (2010). Poliquetos (Annelida). En S. Palma, P. Báez \& G. Pequeño (Eds.), Bibliografía sobre biodiversidad acuática de Chile (pp. 159172). Comité Oceanográfico Nacional, Valparaíso.

Rozbaczylo, N., Moreno, R. A., \& Díaz-Díaz, O. (2017). Poliquetos bentónicos en Chile: pp. 51-70. En O. Díaz-Díaz, D. Bone, C. T. Rodríguez \& V. H. DelgadoBlas (Eds.), Poliquetos de Sudamérica. Volumen especial del Boletín del Instituto Oceanográfico de Venezuela. Cumaná, Venezuela.

Rouse, G. \& Fauchald, K. (1997). Cladistic and polychaetes. Zoologica Scripta, 26(2), 139204.

San Martín, G. (1984). Estudio biogeográfico, faunístico y sistemático de los poliquetos de laa familia Sílidos (Syllidae: Polychaeta) en Baleares. Publicaciones de la Universidad Complutense de Madrid No. 187, Madrid, $581 \mathrm{pp}$.

San Martín, G. (1984). Descripción de una nueva especie y revisión del género Sphaerosyllis (Polychaeta: Syllidae). Cahiers de Biologie Marine, 25, 375-391.

San Martín, G. (2003). Annelida Polychaeta II. Syllidae. En M. A. Ramos, et al. (Eds.), Fauna Ibérica, vol. 21 (554 pp.). Museo Nacional de Ciencias Naturales. CSIC. Madrid

San Martín, G. (2005). Exogoninae (Polychaeta: Syllidae) from Australia, with the description of a new genus and twenty-two new species. Records of the Australian Museum, 57(1), 39-152.

San Martín, G., \& Hutchings, P. (2006). Eusyllinae (Polychaeta: Syllidae) from Australia with the description of a new genus and fifteen new species. Records of the Australian Museum, 58, 257-370.

San Martín, G., \& Aguado, M. T. (2014). Family Syllidae. En Phyllodocida: Nereidiformia. Handbook of Zoology, Annelida. A Natural History of the Phyla of the Animal Kingdom. Verlag Walter der Gruyter $\mathrm{GmbH}$ \& Co. Schmidt- Rhaesa, A. (Ed. In chief), $52 \mathrm{pp}$. 
San Martín, G., \& Parapar, J. (1997). "Errant" polychaetes of the Livingston Island Shelf (South Shetlands, Antarctica), with the description of a new species. Polar Biology, 17, 502-514.

San Martín, G., González, G., \& López-Jamar, E. (1985). Aspectos sistemáticos y ecológicos sobre algunas especies de Sílidos (Polychaeta: Syllidae) de las costas gallegas. Boletín del Instituto Español de Oceanografía, 2(2), 27-36.

San Martín, G., Hutchings, P., \& Aguado, M. T. (2008). Syllinae (Polychaeta, Syllidae) from Australia. Part. 1. Genera Branchiosyllis, Eurysyllis, Karroonsyllis, Parasphaerosyllis, Plakosyllis, Rhopalosyllis, Tetrapalpia n. gen., and Xenosyllis. Records of Australian Museum, 60(2), 119-160.

San Martín, G., López, E., \& Aguado, M. T. (2009). Revisión de Pionosyllis (Polychaeta: Syllidae: Eusyllinae), with a cladistic analysis, and the descripction of five new genera and two new species. Journal of the Marine Biological Association of the United Kingdom , 89(7), 1455-1498.

San Martín G., \& Worsfold, T. M. (2015). Guide and keys for the identification of Syllidae (Annelida, Phyllodocida) from the British Isles (reported and expected species). ZooKeys, 488, 1-29.

Siewing, R. (1955). Petitia amphophthalma n. gen., n. sp. ein neuer Polychaet aus dem Sandlückensystem. Vie et Milieu, 6, 413-425.

Silva, N., \& Palma, S. (Eds.). (2006). Avances en el conocimiento oceanográfico de las aguas interiores chilenas, Puerto Montt a cabo de Hornos. Comité Oceanográfico Nacional - Pontificia Universidad Católica de Valparaíso, Valparaíso, $162 \mathrm{pp}$.

Simon, C., San Martín, G., \& Robinson, G. (2014). Two new species of Syllis (Polychaeta: Syllidae) from South Africa, one of them viviparous, with remarks on larval development and vivipary. Journal of the Marine Biological Association of the United Kingdom, 94(4), 729-746.

Soto, E. H., \& San Martín, G. (2017). New reports and a new species of Syllidae (Annelida) from Chilean Patagonia. Journal of the Marine Biological Association of the United Kingdom. doi: 10.1017/ S0025315417001242.

Soto, E. H., San Martín, G., \& Peñaloza, M. (En prensa). Exogoninae (Annelida: Syllidae) from Chilean Patagonia. Zootaxa.

Wesenberg-Lund, E. (1962). Polychaeta Errantia. Reports of the Lund University Chile Expedition, 43. Acta University of Lund, 57(12), 1-139.

Westheide, W. (1974). Interstitielle fauna von Galapagos XI. Pisionidae, Hesionidae, Pilargidae, Syllidae (Polychaeta). Mikrofauna Meeresboden, 44, 1-146. 